\title{
Nosh
}

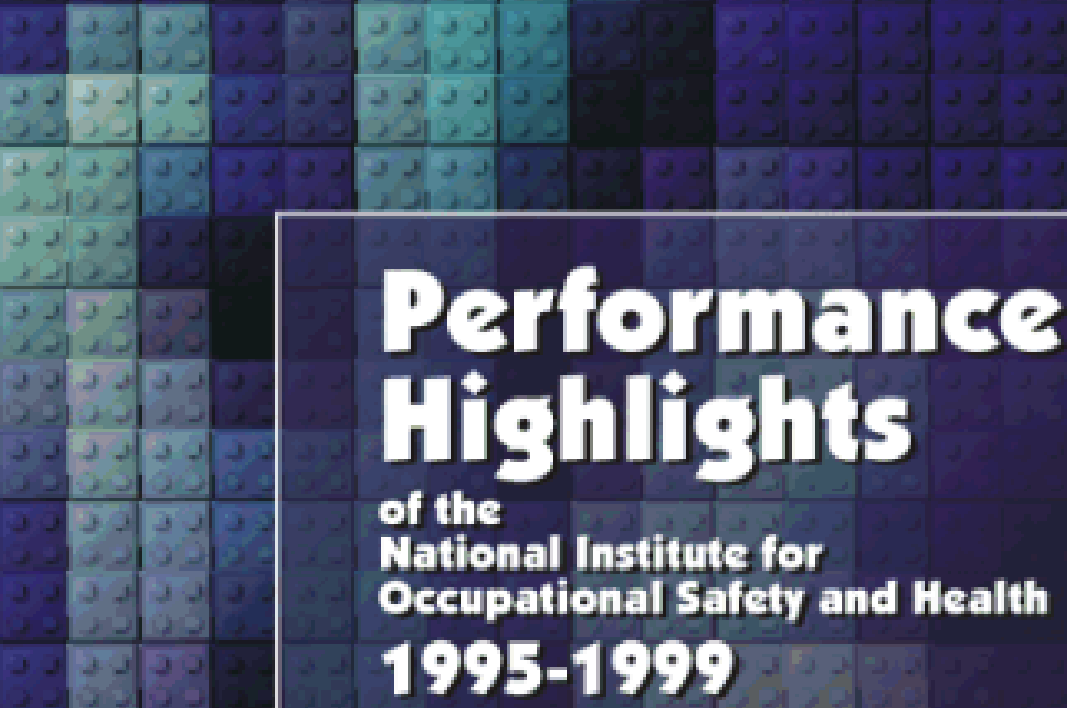

U.S. DEPART MENT OF HEALTH AND HUMAN SERVICES Public Health Service

Centers for Disease Control and Prevention

Natiknal Institute for Occupational Safety and Health

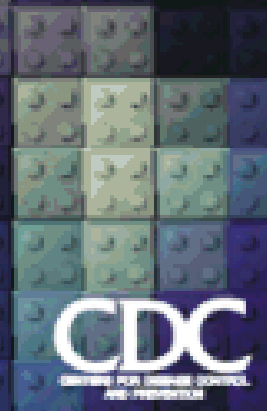




\section{Performance Highlights of the National Institute for Occupational Safety and Health 1995 - 1999}

Prepared in Compliance with the Government Performance and Results Act (GPRA)

March 31, 2000 


\section{Foreword}

\section{Highlights of NIOSH Performance for Fiscal Years 1995 - 1999}

This report presents highlights of NIOSH progress and performance over the past five years. It is organized around the NIOSH Strategic Plan, which provides the framework for performance goals and indicators required by the Government Performance and Results Act of 1993 (GPRA). These goals encompass the functions deemed critical to the protection and promotion of worker health and safety: research; surveillance; prevention intervention; and information, training, and capacity to prevent occupational diseases and injuries.

While GPRA requires annual reporting of performance, this report covers a five-year period. This longer time frame facilitates a more valid assessment of the results and impacts of investment in research activities, many of which take several years to complete. Annual reports of NIOSH performance are contained in the CDC Congressional Budget Justifications submitted to the Office of Management and Budget each year.

In creating NIOSH as the nation's primary research agency for worker health and safety, Congress recognized that NIOSH must rely on others in the occupational safety and health community to have an impact on the overall level of hazards, injuries, and illnesses in the workplace. NIOSH has developed initiatives and programs to create and nurture partnerships with these other stakeholders in pursuit of this common mission. With efforts focused on its four strategic goals, NIOSH will continue to provide leadership in delivering on the nation's promise of a safe and healthful workplace for all.

The highlights in this report help illustrate the magnitude and importance of our mission and the results of our efforts to protect and promote the health of our nation's workforce.

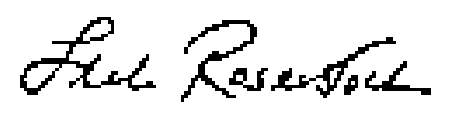

Linda Rosenstock, MD, MPH

Director,

National Institute for Occupational Safety and Health 


\section{Contents}

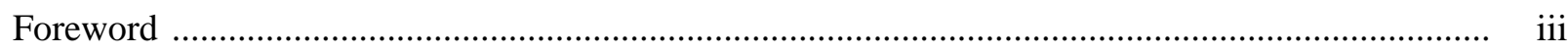

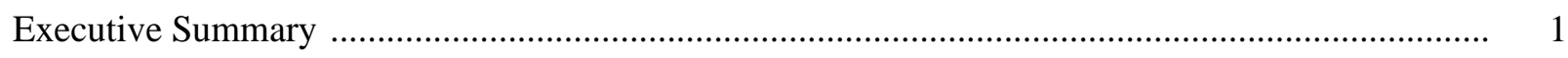

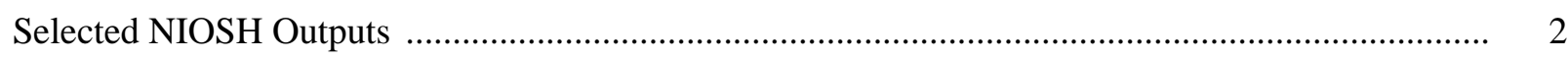

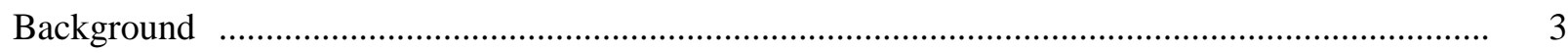

Strategic Goal 1: Conduct a Targeted Program of Research .................................................... 5

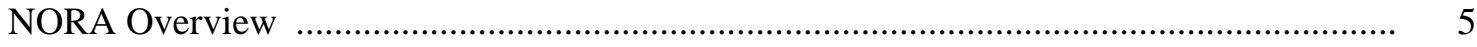

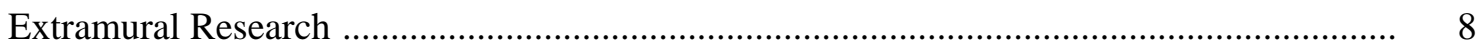

Cooperative Agreements ................................................................................. 11

Intramural Research ................................................................................................... 15

Creating, Testing, and Transferring Technology for Research

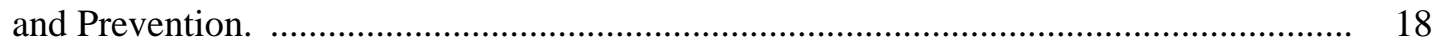

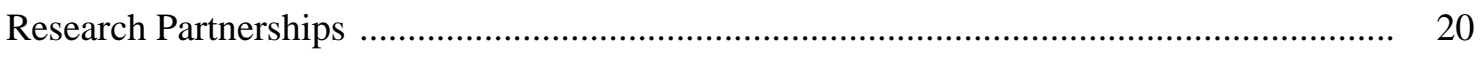

Strategic Goal 2: Develop a System of Surveillance ............................................................ 22

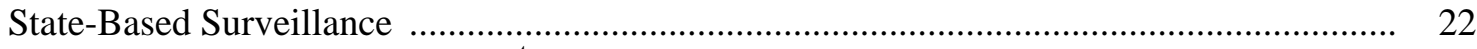

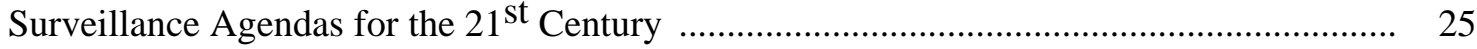

Strategic Goal 3: Increase Prevention Activities ................................................................... 26

Scientific Support for Public Health Policy Development ............................................ 31

Providing National Respirator Certification and Quality Assurance ................................. 33

Strategic Goal 4: Provide Information, Training, and Capacity ................................................ 35

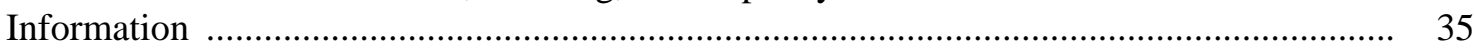

Training Occupational Safety and Health Professionals and Researchers .......................... 39

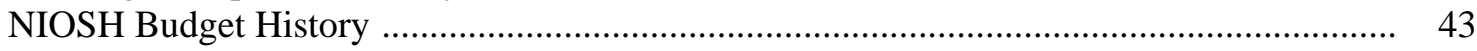

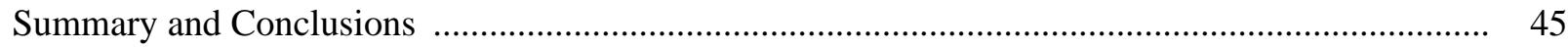




\section{Executive Summary}

The National Institute for Occupational Safety and Health (NIOSH) pursues active programs of research, surveillance, prevention interventions, information dissemination, and health professional education in order to accomplish its statutory mission. These programs span the spectrum of activities necessary for the prevention of work-related illness, injury, disability, and death-beginning with problem identification through etiologic research and surveillance and concluding with development, dissemination, and evaluation of recommendations, technologies, and strategies for prevention. This document demonstrates and highlights NIOSH accomplishments over the past five years.

\section{NIOSH Accomplishments}

\section{Research}

- Established and focused resources on research priorities through the National Occupational Research Agenda (NORA).

- Leveraged resources of other federal agencies to support NORA.

- Pursued an active program of extramural and intramural research.

- Developed research partnerships and collaborations with stakeholders.

\section{Surveillance}

- Funded state-based surveillance.

- Funded and maintained national databases of occupational injuries and fatalities.

- Collaborated with other federal agencies involved in surveillance activities.

- Planned with broad stakeholder involvement to address surveillance needs of the 21st century.

\section{Prevention Interventions}

- Conducted health hazard evaluations to investigate occupational health and safety problems in individual workplaces.

- Investigated fatal incidents and formulated/disseminated prevention strategies.

- Certified and assured the quality of respirators.

- Provided scientific support for public health policy development by recommending the development of new standards, providing information during rulemaking, and participating in federal policy bodies.

\section{Information, Training, and Capacity}

- Devel oped and disseminated policy, technical, and educational documents in printed, audiovisual, and electronic formats.

- Provided information and technical assistance via the web and a toll-free telephone service.

- Trained occupational safety and health professionals and researchers through regional education and research centers and state-based training programs.

- Evaluated the effectiveness of worker training programs. 


\section{Selected NIOSH Outputs}

Increased Federal funding for NORA
FY 96 NIOSH:
$\$ 15.4$ million
FY $98 \mathrm{NIOSH}$ :
$\$ 46.9$ million
FY 96 All Federal: $\quad \$ 30$ million
FY 98 All Federal: $\quad \$ 70$ million

$204 \%$ increase

$133 \%$ increase

Increased NIOSH funding of extramural research grants
FY 96 NIOSH:
$\$ 14.0$ million, $50 \%$ in NORA priority areas
FY 99 NIOSH:
$\$ 29.9$ million, $92 \%$ in NORA priority areas

$107 \%$ increase

Increased number of grants reviewed and funded
FY 96:
FY 99:
65 reviewed
FY 96:
220 reviewed
FY 99:
9 funded ( $14 \%$ success rate)
51 funded ( $23 \%$ success rate)

$238 \%$ increase

$467 \%$ increase

Increased NORA intramural research
FY 96:
$\$ 8.7$ million
FY 99:
$\$ 34.4$ million

$295 \%$ increase

Increased grants for NORA research on intervention effectiveness
FY 96:
FY 99:
$\$ .5$ million
$\$ 4.6$ million

$820 \%$ increase

Increased Federal NORA funding partners
FY 98:
FY 00:
3 NIH partners
$10 \mathrm{NIH}$ partners and EPA

$233 \%$ increase

Increased patent filings by NIOSH scientists for engineering solutions
FY 96:
FY 00:
2 patent filings
7 patent filings

$250 \%$ increase

Increased NIOSH scientific publications in peer-reviewed journals
FY 95:
FY 98:
184
234

$27 \%$ increase

Increased NIOSH policy, technical and educational documents
FY 95:
FY 99:
26

$333 \%$ increase

Increased NIOSH 800 number calls
FY 95:
FY 99:
88,432
148,782

$69 \%$ increase

Increased NIOSH Web Hits
FY 95:
FY 99:
333,429
$14,866,831$

$4,359 \%$ increase

Increased Health Hazard Evaluations

$\begin{array}{ll}\text { FY 95: } & 318 \\ \text { FY 99: } & 334\end{array}$

$5 \%$ increase

Increased Respirator Certifications
1980-1984
Average of 123 annually
1995-1999
Average of 723 annually
$488 \%$ increase 


\section{Background}

The National Institute for Occupational Safety and Health (NIOSH) is the primary federal agency responsible for conducting research and making recommendations for the prevention of work-related illness and injury. NIOSH is located in the Department of Health and Human Services (DHHS) in the Centers for Disease Control and Prevention (CDC).

The NIOSH mission is to provide national and world leadership to prevent workrelated illness, injury, disability, and death by gathering information, conducting scientific research, and translating the knowledge gained into products and services. The breadth of this mission is unique in public health, tantamount to the research emphasis of the National Institutes of Health $(\mathrm{NIH})$ and the prevention services emphasis of other programs within the CDC. This dual role is reflected in NIOSH activities, outputs, and impacts, described below within the framework of the Institute's four strategic goals.

\section{Strategic Goals}

1. Conduct a targeted program of research to reduce morbidity, injuries, and mortality among workers in high-priority areas and high-risk sectors.

2. Devel op a system of surveillance of major occupational illnesses, injuries, exposures, and health hazards.

3. Increase occupational disease and injury prevention activities through workplace evaluations, interventions, and recommendations.

4. Provide workers, employers, the public, and the occupational safety and health community with information, training, and capacity to prevent occupational diseases and injuries.

The importance of the NIOSH mission is compelling. Each day, an average of 9,000 U.S. workers sustain disabling injuries on the job, 17 workers die from an injury sustained at work, and 137 workers die from work-related diseases. The economic burden of this continuing toll is high. Data from a NIOSH-funded study published in 1997 showed that in 1992, direct and indirect costs of occupational injuries and illnesses totaled $\$ 171$ billion. These costs are compared to costs for other major health problems in the chart at the top of the next page. 


\section{Annual Economic Burden of Disease and Injury, 1992}

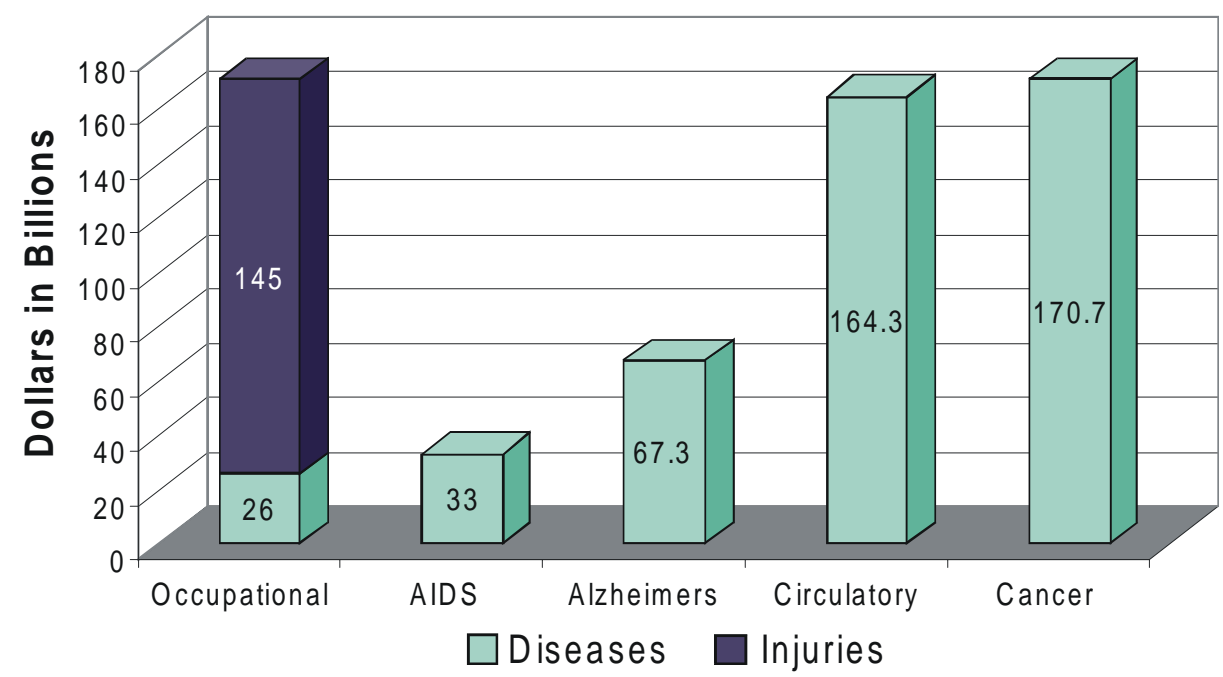

The changing nature of work and of the workforce in the United States, including the accelerating expansion of technology, poses continuing challenges to the prevention of work injury and disease. Nonetheless, progress is occurring. The 1990s have witnessed a small decline in fatal work injuries and decreases in injury and illness rates, despite economic expansion and rapid job growth.

\section{Incidence Rates of Workplace Injuries and Illnesses, United States, 1993-1998 \\ (per 100 workers)}

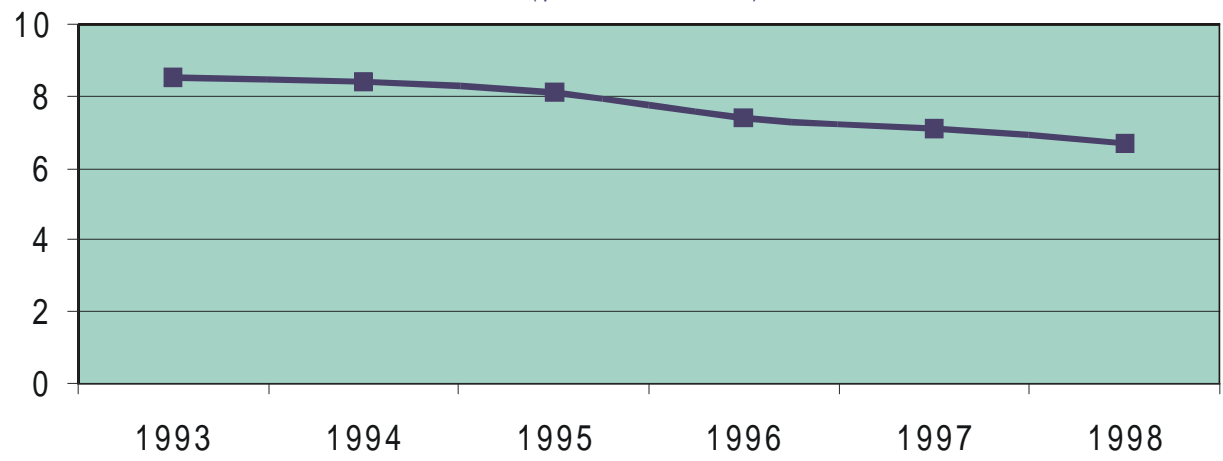

$\mathrm{NIOSH}$ has played a vital role in achieving this progress, but relies on the actions of many intermediaries including employers, employees, and NIOSH partners in other Federal agencies, state and local governments, and the private sector.

Headquartered in Washington D.C., NIOSH has offices in Atlanta, Georgia, and research divisions in Cincinnati, Ohio; Morgantown, West Virginia; Pittsburgh, Pennsylvania; and Spokane, Washington. NIOSH's 1,400 employees work in a wide range of disciplines, including industrial hygiene, epidemiology, nursing, engineering, medicine, and statistics. 


\section{Strategic Goal 1: Conduct a Targeted Program of Research}

\section{NORA Overview}

In 1996, NIOSH and its partners established the National Occupational Research Agenda (NORA), a framework to guide occupational safety and health research into the next decade-not only for NIOSH but for the entire occupational safety and health community. Approximately 500 organizations and individuals outside NIOSH provided input into development of the Agenda. NORA comprises 21 priorities in three categories:

\begin{tabular}{|c|c|}
\hline CATECORY & PRIORITY RESEARCH AREA \\
\hline Disease and Injury & $\begin{array}{l}\text { Allergic and Irritant Dermititis } \\
\text { Asthma and Chronic Obstructive Pulmonary Disease } \\
\text { Fertility and Pregnancy Abnormalities } \\
\text { Hearing Loss } \\
\text { Infectious Diseases } \\
\text { Low Back Disorders } \\
\text { Musculoskeletal Disorders of the Upper Extremeties } \\
\text { Traumatic Injuries }\end{array}$ \\
\hline $\begin{array}{l}\text { Work Environment and } \\
\text { Workforce }\end{array}$ & $\begin{array}{l}\text { Emerging Technologies } \\
\text { Indoor Environment } \\
\text { Mixed Exposures } \\
\text { Organization of Work } \\
\text { Special Populations at Risk }\end{array}$ \\
\hline $\begin{array}{l}\text { Research Tools } \\
\text { and Approaches }\end{array}$ & $\begin{array}{l}\text { Cancer Research Methods } \\
\text { Control Technology and Personal Protective Equipment } \\
\text { Exposure Assessment Methods } \\
\text { Health Services Reseach } \\
\text { Intervention Effectiveness Research } \\
\text { Risk Assessment Methods } \\
\text { Social and Economic Consequences of Workplace } \\
\quad \text { Illness and Injury } \\
\text { Surveillance Research Methods }\end{array}$ \\
\hline
\end{tabular}


The process for developing NORA has been praised as a model of strategic planning using broad stakeholder input: NORA was a semifinalist in the 1998 Innovations in American Government Award and has been cited by numerous organizations, including the Institute of Medicine, the National Association of State Universities and Land-Grant Colleges, and jointly by the American Lung Association and the American Thoracic Society. Seventeen scientific organizations have replicated aspects of the NORA process, with NIOSH consultation:

\begin{tabular}{|l|}
\hline Organizations Using NORA as a Model Approach for \\
Directing Research \\
\hline International and Foreign National Organizations \\
European Agency for Safety and Health at Work \\
Istituto Superiore Per La Prevenzione E La Securezza \\
Del Lavoro (Italy) \\
Japanese National Institute of Industrial Health \\
Norwegian National Institute of Occupational Health \\
Federal Agencies and Programs \\
Agency for Toxic Substances and Disease Registry \\
Chemical Safety and Hazard Investigation Board \\
Department of Defense, Deployment Toxicology Research \\
and Development \\
Environmental Protection Agency, Human Health Indoors \\
Project \\
National Center for Health Statistics \\
National Center for HIV, STD and TB Prevention \\
National Center for Injury Prevention and Control \\
National Committee on Vital and Health Statistics \\
State Agencies Conducting Occupational Health Research \\
California \\
Maine \\
Washington State \\
Non-Profit Research Organizations \\
Chemical Industry Institute of Toxicology \\
Pacific Northwest Agricultural Safety and Health Center \\
\hline
\end{tabular}


NORA is distinctive not only for the process by which it was developed, but also for the continued partnership between NIOSH and over 200 organizations to ensure the agenda is implemented. The impact of this continued partnership is farreaching. In 1999, associations representing occupational safety and health professionals jointly surveyed their membership on the impact of NORA ( $N=948)$. Among the 42 percent of respondents aware of NORA, some of the principal findings of the survey are provided below:

\section{Survey of Safety and Health Professionals on NORA I mpact}

- 30 percent - Changed the research priorities of their organization.

- 20 percent - Increased funding for organization's research (no respondents reported a decrease).

- 35 percent - Increased partnerships between researchers.

- 35 percent - Increased partnerships between organizations.

- 47 percent - Increased the quality of occupational safety and health research.

These findings are amplified by statements from a variety of informed health leaders and policymakers:

"NORA initiatives are so important because they base themselves on the kinds of interactions that will have to become central issues for our society as the next century begins.... NORA is a prototype for these kinds of initiatives."

- Kenneth Shine, M.D., President, Institute of Medicine, National Academy of Sciences

"From its [NORA's] beginnings, NIOSH and its partners have understood that a prerequisite to making workplaces safer in this new economy is making sure that no one is left out of the decision making process. That's really the genius of NORA... I've encouraged all my staff to use NORA as a model for building strong research partnerships."

\section{- Donna Shalala, Ph.D., Secretary, U.S. Department of Health and} Human Services

"NORA is vitally important. It is important because it provides clear focus and sets priorities on health and safety issues. It is important because it is resulting in significantly more resources directed toward the 21 priority areas. And it is increasing our understanding through the research, it is helping us anticipate, identify and provide innovative solutions to health and safety concerns and to prevent injuries and illnesses before they occur."

- Lawrence Burns, Ph.D., Vice President for Research, Development and Planning, General Motors Corporation 
"By coming together with others who care about the costs of occupational injuries and illnesses, both in human and economic terms, we all benefit. It is also important that NORA's agenda emphasize not only medical problems but the social and economic concerns also. At the Building and Construction Trades Department, representing more than three million workers, ... we are very proud to be partners in NORA."

- Robert Georgine, President, Building and Construction Trades Department, AFL-CIO

\section{Extramural Research}

\section{Research Grants}

NIOSH is fully integrated into the National Institutes of Health $(\mathrm{NIH})$ grants system, with all submitted proposals reviewed by a standing NIH Study Section composed of leading extramural scientists.

NIOSH Grant Funding Success 1990-1999

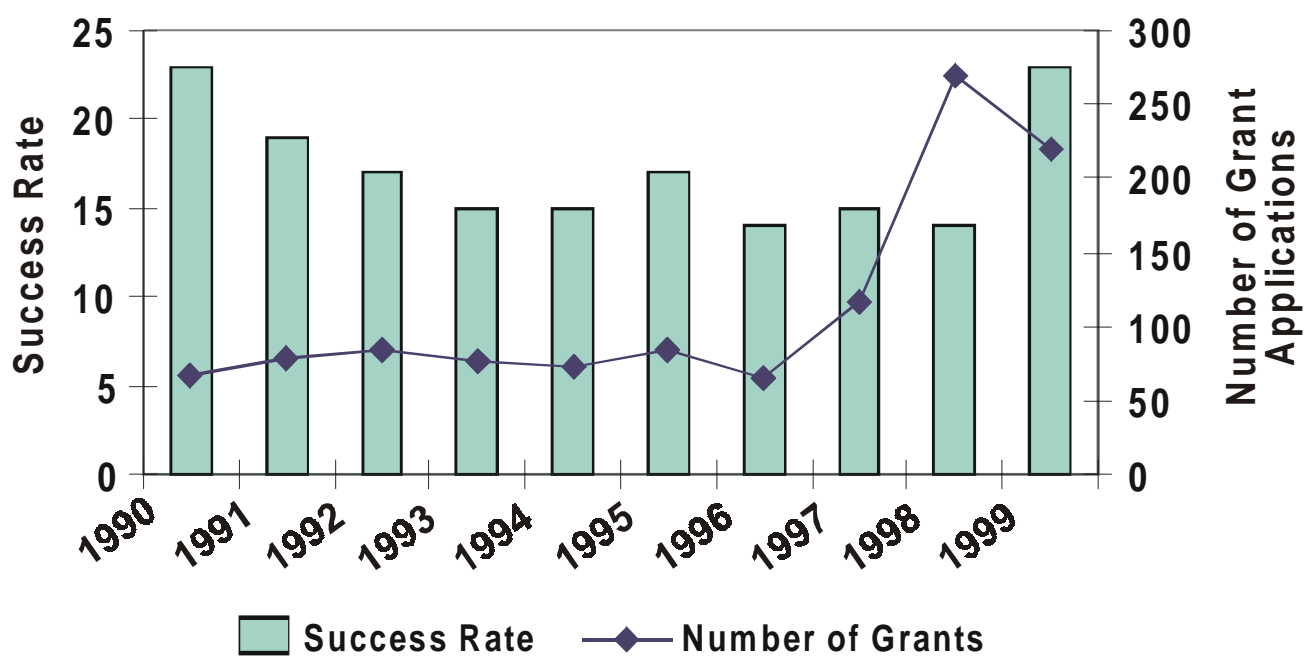

Assuring scientific quality is one aspect of NIOSH grants output. The other is ensuring NIOSH grants address topics considered most essential to advancing worker safety and health. NIOSH has rapidly aligned its extramural research grants program with the priorities established by NORA, and has increased overall the investment in extramural investigator-initiated awards. In 1996, NIOSH invested \$14 million in extramural grants (50 percent were in NORA priority areas). In 1999, the investment climbed to $\$ 29$ million, with 92 percent in NORA priority areas. 
Attracting extramural researchers to apply their talent in occupational safety and health has been a leading priority of NIOSH during the Clinton Administration. Increasing research grant funding is critical to this aim. NIOSH allocates threequarters of new funding to expand extramural research (new NORA funding was first appropriated in 1998).

\section{Federal NORA Spending FY96 and FY98}

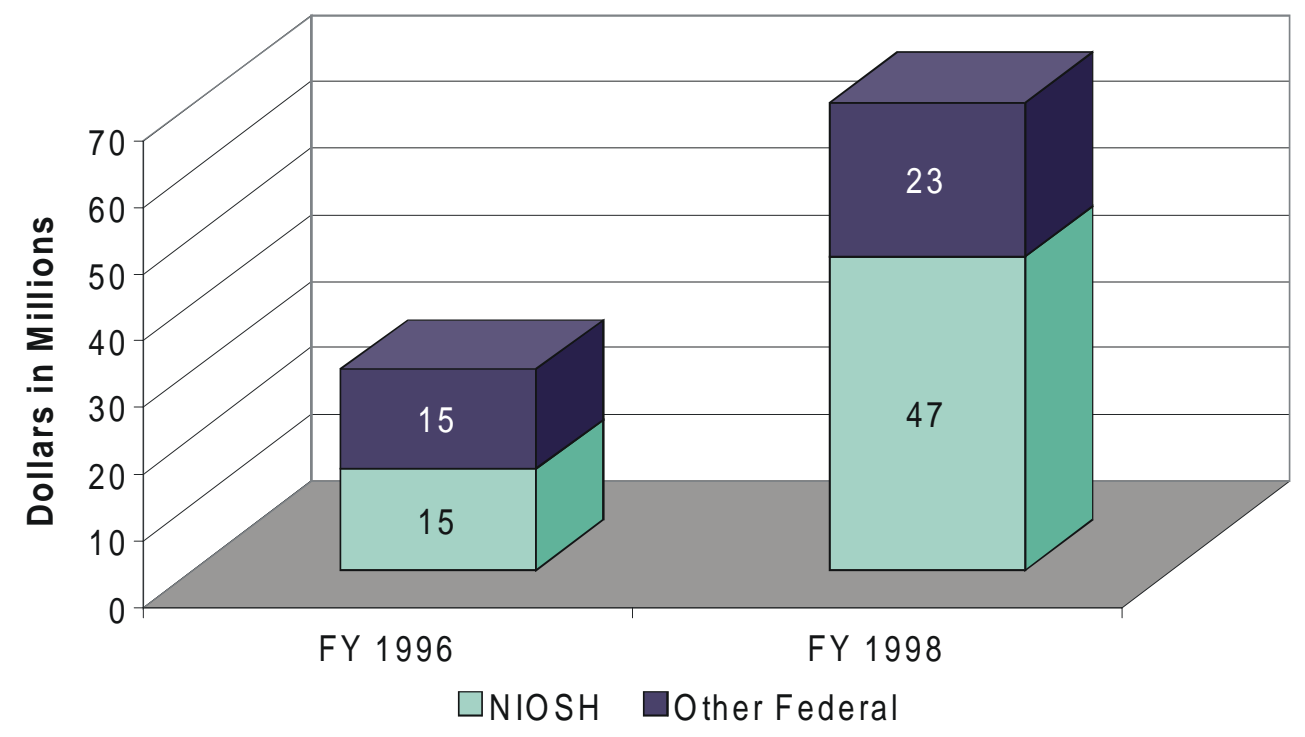

The success of NORA in attracting research talent to occupational safety and health continues to outstrip the ability of NIOSH to fund high-rated research proposals. The NIOSH success rate for grants funding (the percentage of qualified research proposals that are funded) still lags substantially behind that of $\mathrm{NIH} \mathrm{(23}$ percent vs. 32 percent in 1999). The consequences of a disparately low success rate is loss of interested investigators to research fields with higher probability of funding. NIOSH has worked hard through NORA to continue to generate enthusiasm among the research community despite low success rates, and has experienced a dramatic increase in submitted and approved grants, particularly in NORA priority areas. 
Another measure of NORA impact is the ability of NIOSH to obtain co-sponsors for occupational safety and health research grants announcements from other programs and agencies. J oint funding has steadily increased for NORA, with three NIH partners in 1998, four in 1999, and in FY 2000 ten NIH partners and the Environmental Protection Agency. By leveraging research dollars of others, $\mathrm{NIOSH}$ has been able to extend the reach and impact of the NORA agenda. NIOSH still remains the primary source of all federal occupational safety and health research, accounting for 85 percent of the $\$ 218$ million identified government-wide in FY 1998.

Another NIOSH-NORA success is shifting the spectrum of occupational safety and health research to achieve more balance between etiologic research-problem identification and characterization-and problem-solving research. Highlighting this trend is the growth of intervention effectiveness research grants supported by $\mathrm{NIOSH}$, from $\$ 500,000$ in 1996 to $\$ 4.6$ million in 1999. Current grants for intervention research address many subjects of high concern among the general public and policy makers. These include projects that will evaluate:

- Training in lifting techniques to prevent back injuries.

- Preventing hearing loss among construction workers.

- Preventing silica exposure among construction workers.

- A joint strategy by OSHA and the construction industry to prevent fatalities, injuries, and illness among home builders.

- Reducing musculoskeletal disorders and traumatic injuries among dairy and vegetable produce farmers.

- Preventing back and shoulder injuries among nursing home workers.

- Ergonomic interventions to reduce muscul oskel etal disorders among office workers.

These studies provide crucial information to employers, workers, and others on the effectiveness of specific strategies for the prevention of injury and illness. For example, a NIOSH-funded study recently published in the J ournal of Infection Control Hospital Epidemiology documented great reductions (as much as 93 percent) in sharps and needlestick injuries achieved by a highly replicable intervention strategy integrating administrative, engineering, and behavioral elements. Information on effectiveness is also essential to public health programs and regulators as a basis for benefit and cost analyses to inform program and policy decisions. 


\section{Cooperative Agreements}

NIOSH has 111 cooperative agreements in 36 states and 3 countries for collaborative research and prevention activities.

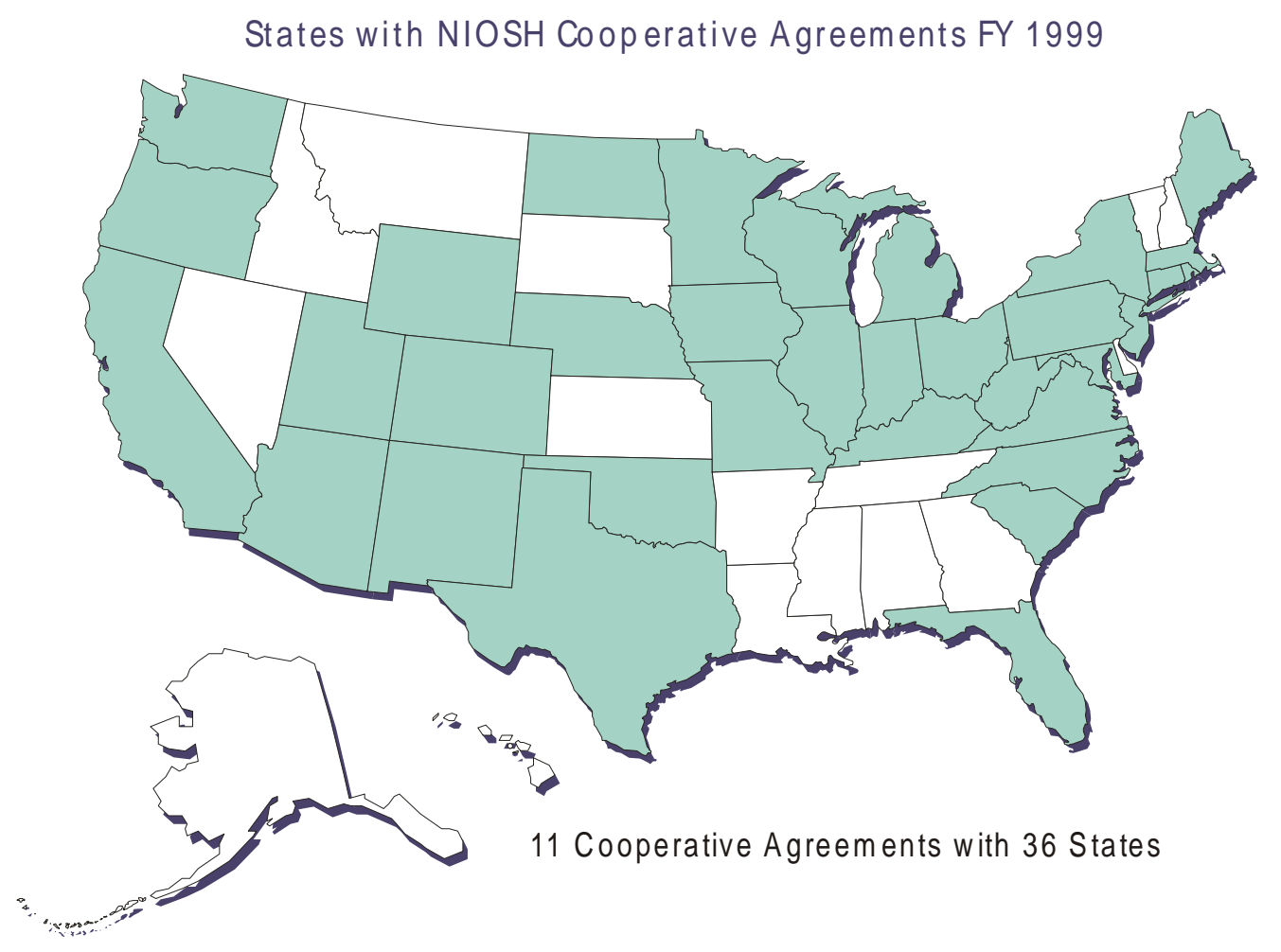

\section{Sector Specific Research}

Since 1990, the majority of NIOSH research cooperative agreements have targeted two industry sectors - agriculture and construction. Although overall fatal work injuries and injury and illness rates are declining, agriculture and construction, together with mining (a focus of extensive intramural research), consistently lead the Nation in occupational fatalities and sustain high levels of disabling and serious injury and illness. However, these sectors are safer today than they were a decade ago. Since 1991, NIOSH has received funding for initiatives in both construction and agriculture. The rates of work-related injuries resulting in medical treatment, lost time from work, or restricted work activity have steadily decreased in both sectors. Similar injuries to healthcare workers are on the rise (see graphic on next page). Based on this disturbing trend in healthcare, NIOSH developed a healthcare worker initiative in 1999 to address issues in this sector. Unlike the construction and agriculture initiatives, the healthcare worker effort is not receiving specific funding. 


\section{Trends Across Sectors}

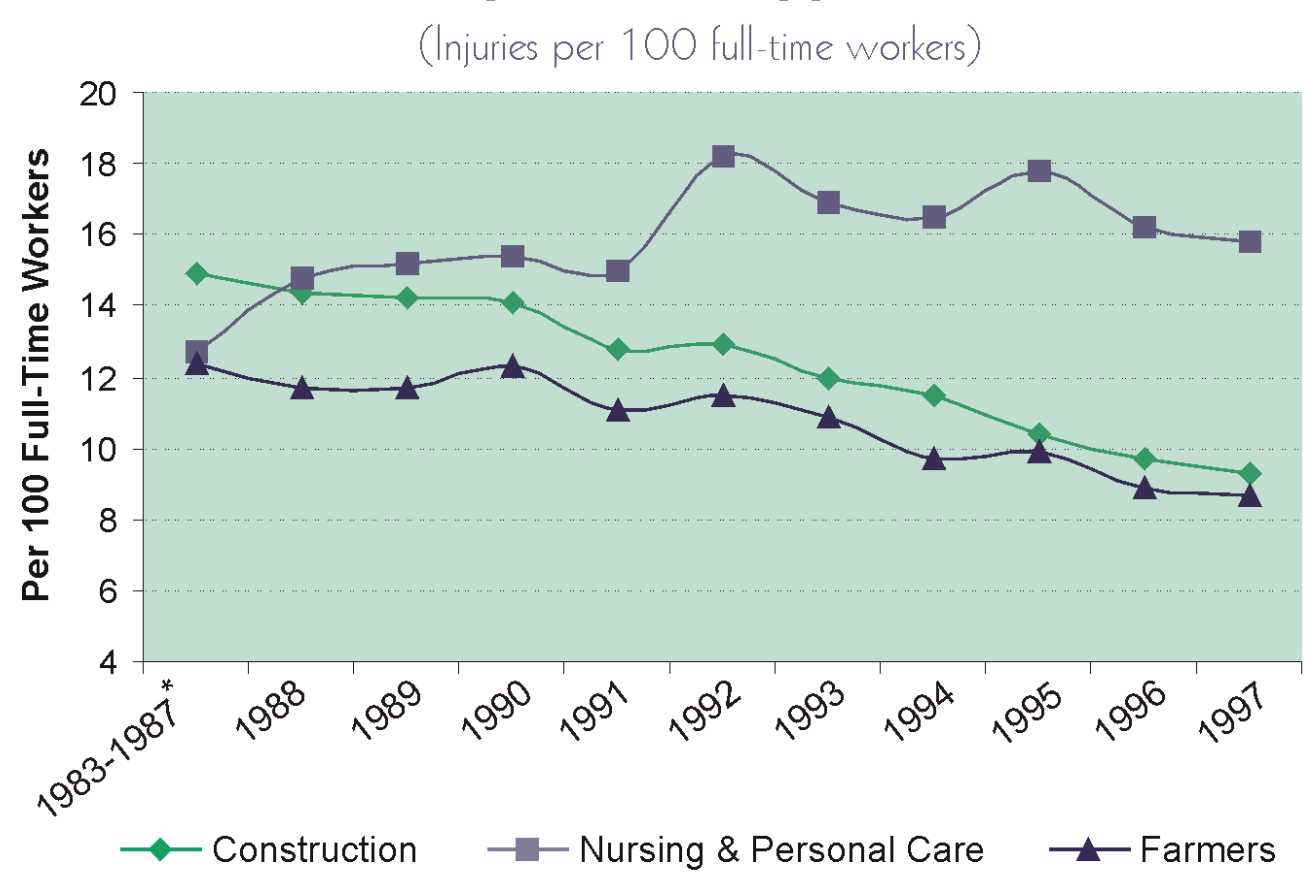

Source: Annual Survey of Occupational Injuries and Illnesses (BLS)

*Baseline

\section{Agriculture}

NIOSH coordinates a wide range of collaborative extramural efforts, predominantly among universities, but also including state and local health departments and other industry, worker, and community partners. Nine NIOSH Agricultural Research Centers are a cornerstone of this effort, serving geographically distinct regions. These Centers of Excellence focus on research, education, and prevention. Community Partners for Healthy Farming funds activities in 12 states in both surveillance and intervention activities, and an additional program focuses exclusively on protecting youth on farms from injury and hazardous exposures (see map at top of next page).

In 1995, NIOSH funded an evaluation of this extramural research program, with oversight of the NIOSH Board of Scientific Counselors. The evaluation found the program had successfully initiated an essential level of research (beginning from a practically non-existent research base). This investment in research is paying off. The following examples illustrate how research is being applied to prevention: 


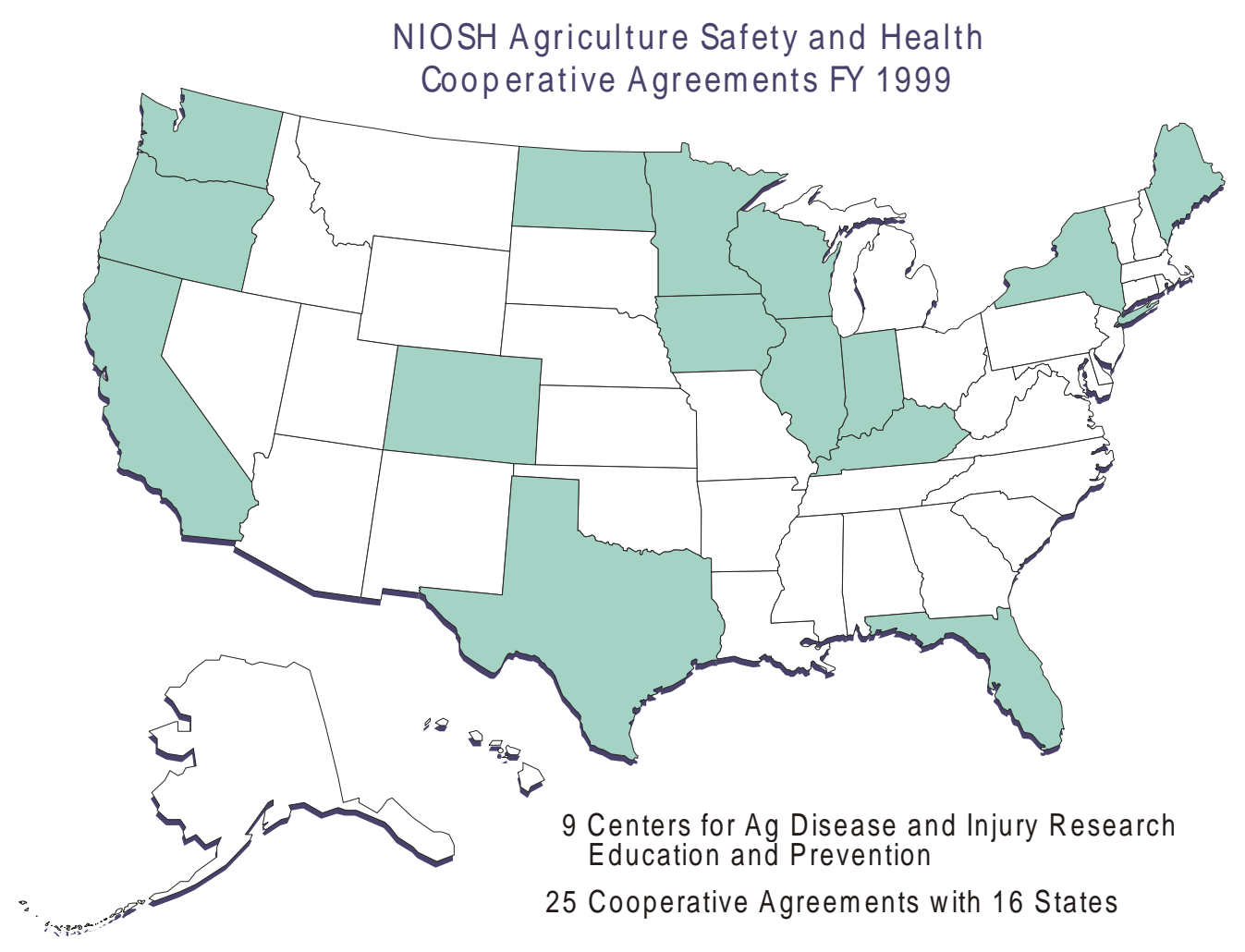

- The leading cause of fatalities among farmers is tractor rollovers. Many farmers continue to use older tractors without effective roll-over protection structures (ROPS). NIOSH has supported and collaborated in research to increase the retrofitting and appropriate use of ROPS, addressing engineering and behavioral factors that have impeded use of ROPS. This research is leading to more effective educational efforts to increase farmers' willingness to invest in tractor retrofits. In two counties in Kentucky last year, research-based education to encourage purchase of ROPS to prevent tractor-related injuries and deaths resulted in the purchase of 69 retrofit kits-as compared to 4 kits in the prior year.

- Work-related musculoskel etal disorders are prevalent in almost every agricultural industry. In Sonoma County, California, researchers collaborated with the wine/grape industry to reduce the weight of the picking container by 19 percent (from 57 to 46 pounds). As a result, workers reported significant reduction in back symptoms and recovery time and are reporting less neck, shoulder, and knee pain, while maintaining their productivity. 
- The results of agricultural safety and health research, together with prevention information derived from this research (e.g., guidelines, safety training, and communication programs and materials) and other relevant information (e.g., EPA and OSHA regulations and materials) are disseminated through a web-based electronic library and CD ROMs. The website receives 400,000 hits per month.

\section{Construction}

NIOSH supports an extramural research and prevention program in construction. Organized labor is a critical partner in this effort. The high rates of turnover and contingent employment relationships that characterize the industry make labor's unique access to employment and health information on construction workers particularly important. The program includes university-based collaborating research programs in six states, spearheaded by the Center to Protect Workers' Rights (CPWR), a nonprofit research center for the construction industry which is partially funded by NIOSH.

Research on construction hazards and the construction workforce are being translated into injury and illness prevention. The following activities are examples:

- CPWR developed a standardized safety and health hazard awareness training program for construction workers, which has been adopted by the Building and Construction Trades Department, AFL-CIO, and its employers. The program has been recognized by OSHA as a model training program for the industry, and to date approximately 50,000 construction workers have been trained. Employers have partnered with CPWR to fund and disseminate this program.

- CPWR and its collaborators developed a certification program for employers designed to address critical factors for the prevention of falls, a leading cause of fatal and non-fatal injuries in construction. The program has been successfully piloted in West Virginia, and is now being expanded nationally. The St. Paul I nsurance Company is now offering it to all construction employers it insures, for both workers compensation and liability, providing a 5 percent rebate as an incentive to participate.

- CPWR disseminates a wide variety of hazard information in forms practical for construction employers and workers, in Spanish and English version, and through print and electronic media. 
Health Care Industry

A more recent work sector focus for research cooperative agreements is occupational safety and health in the health care industry. Health care workers currently represent 8 percent of the U.S. workforce, and health care services are growing at twice the rate of the overall economy. As the population ages, the number of health care workers is increasing, especially among lower-paid jobs, such as nursing home attendants and home health aides. In contrast to the workforce as a whole, occupational injuries and illnesses are actually rising in this sector.

$\mathrm{NIOSH}$ is addressing major hazards in this industry through both intramural and extramural research. This research has been highly productive, translating into important findings and prevention activities.

For example, NIOSH intramural research on latex allergies contributed to critical elements of NIOSH recommendations published in 1997 to prevent the increasing prevalence of latex allergies among health care workers. These recommendations, comprising the first federal identification of the problem, include selection of powder-free gloves with low protein content and the substitution of non-latex gloves when possible. These guidelines have been widely supported and adopted in policy at the Food and Drug Administration, OSHA, and other federal and state health and safety agencies.

Similarly, findings of NIOSH-funded researchers have contributed to recently issued NIOSH recommendations for preventing needlestick injuries among health care workers. These recommendations have received wide coverage by national news media and are helping to drive policy decisions at the state and federal levels.

From 1995 to 1999, NI OSH has funded cooperative agreements with institutions in five states to extend and target existing health care worker research capacity. Current research among these collaborators focuses on preventing latex allergies and occupational transmission of blood borne pathogens and tuberculosis.

\section{Intramural Research}

$\mathrm{NIOSH}$ is recognized nationally and internationally as the premier institute in occupational safety and health research; its staff of 1,400 is the largest devoted to occupational safety and health in the world. NIOSH has aggressively aligned its intramural research programs with NORA. In the three years since NORA was established, NORA research has risen from 14 percent to 32 percent of the Institute's research portfolio (a quality assurance team validates projects identified as NORA research are indeed focused on specific NORA priorities). 


\section{NIOSH Intramural Research Budget}

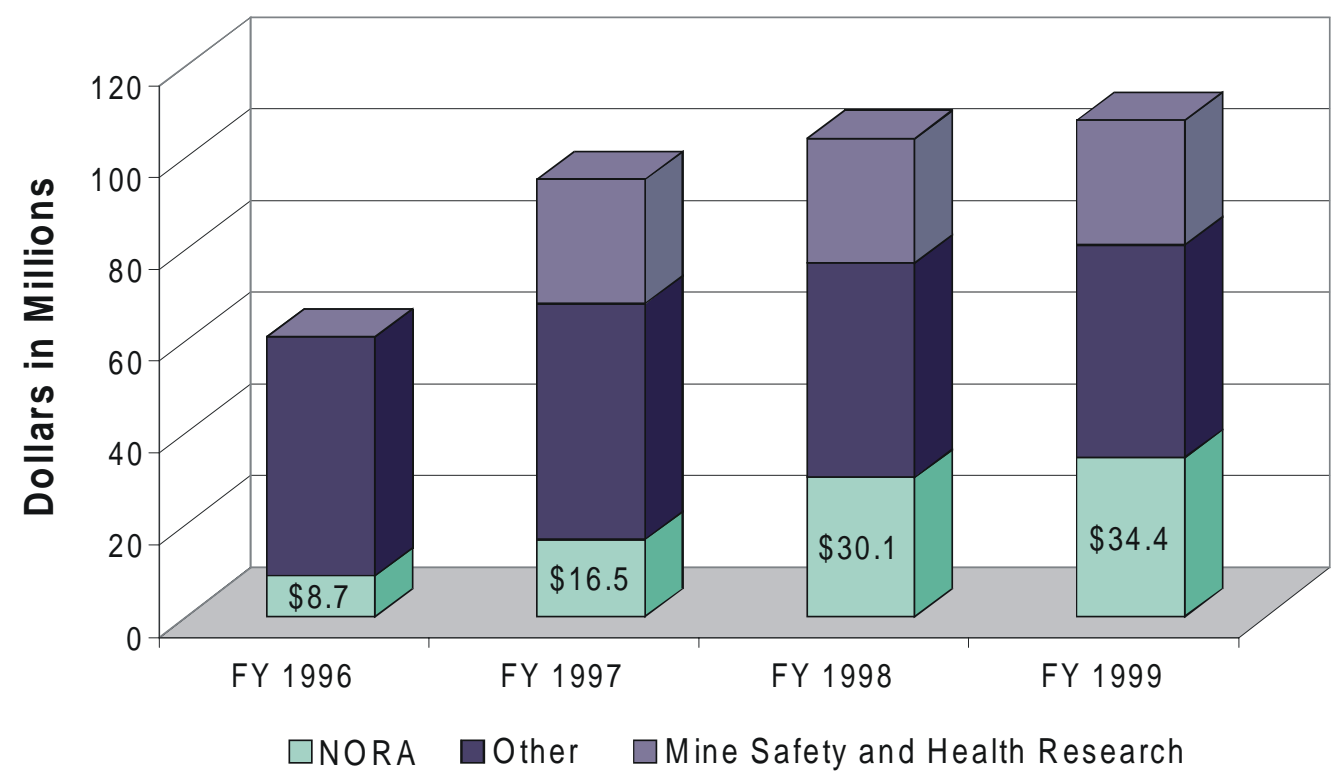

A primary measure of NIOSH research productivity is publication in peer-reviewed scientific journals, which increased from 184 to 234 (27 percent) between 1995 and 1998.

$\mathrm{NIOSH}$ has unique and state-of-the-art laboratory facilities, databases, and expertise, in high demand by the government and private sectors.

- The American Petroleum I nstitute (API) is funding NIOSH to validate biomarker research pioneered by NIOSH scientists to assess the potential adverse neurotoxic effects of gasoline and various oxygenate-gasoline blends. If successful, this validation study will not only enable API to meet EPA testing requirements under the Clean Air Act, it will substantially advance occupational and environmental research and prevention by providing more efficient methods for identifying neurotoxic agents.

- NIOSH is providing facilities and expertise for the Department of Energy to test the use and safety of fuel cell technology as a substitute for diesel engines-which emit potential carcinogens- in vehicles used in mines and other underground and enclosed spaces.

NIOSH scientists continue groundbreaking work in safety and health, as illustrated by key examples in the table on the following page. 


\section{Examples of NIOSH Research Findings}

- Identified glass fibers as possibly carcinogenic, through toxicological research.

- Of relevance to 40,000 workers, identified effective control technology to prevent hazardous paint chemical exposures during coating processes in the autobody repair industry.

- $\quad$ Of relevance to 9 million workers, confirmed through toxicologic research the potential for solvents (toluene) to cause hearing loss comparable to damage caused by hazardous levels and types of noise.

- Documented substantially elevated risk of silicosis and autoimmune diseases among workers exposed to levels permitted by the current OSHA exposure limit.

- Of relevance to 40,000 employees of the Internal Revenue Service and millions of workers in similar work operations, determined the use of a regimen of hourly, brief rest breaks reduced musculoskeletal disorders without loss of productivity.

- Developed engineering controls that reduce biomechanical stressors among beverage delivery workers, who have twice the rate of lost workdays as manufacturing overall.

- $\quad$ Of relevance to almost 2 million nursing home workers, as well as hospital and home healthcare workers, identified mechanical lifting technology effective in reducing ergonomic hazards, responsible for an escalating rate of back injuries.

- Documented a 90 percent reduction in drywall dust emissions (a silicosis risk to construction workers) with the use of commercially available ventilated dry-wall sanders.

- Documented elevated blood lead levels (exceeding CDC recommendations) among children of construction workers, resulting from contamination of workers and their work clothes.

- Documented an unrecognized high prevalence of silica exposures among surface miners, leading to preventive measures in industry and by MSHA.

- $\quad$ Of relevance to one million workers, compiled evidence of a new disease, hypersensitivity pneumonitis, associated with exposure to airborne metal working fluids used in machining operations.

- Identified a strong association between benzene exposure (which causes leukemia and other blood disorders) and suppressed blood cell counts in exposed workers, supporting OSHA regulatory requirements for blood monitoring among benzene-exposed workers.

- Evaluated an employee-management team approach to reducing ergonomic hazards in the nursing home industry which lowered lost and restricted workdays by 70 percent.

- Documented that more than 90 percent of miners have a level of hearing impairment affecting daily communication (compared to nine percent of males in the general population), prompting prevention efforts in the mine industry and regulatory action by the Mine Safety and Health Administration.

- $\quad$ Elucidated the toxicological mechanisms by which inhaled metal exposures may be causing lung cancer, providing direction for research on antioxidant treatments for preventing cancer and a scientific basis for OSHA setting exposure limits on certain metals.

- $\quad$ Determined physical characteristics of fibers implicated in pulmonary toxicity, providing important data for improving the design of industrial processes and products to prevent occupational lung cancers and lung fibrosis.

- $\quad$ Pioneered and tested the use of gloves for handling pesticide-treated plants in greenhouse operations, reducing workers' compensation claims and long-term toxicologic risks for greenhouse workers.

- Identified cab filtration systems on underground mine vehicles that reduce hazardous dust exposures by 90 percent.

- Determined that water mist systems are effective as chemical systems for fire suppression in underground mines, eliminating a potentially toxic exposure.

- Determined that water mist systems are effective as chemical systems for fire suppression in underground mines, eliminating a potentially toxic exposure. 


\section{Creating, Testing, and Transferring Technology for Research and Prevention}

\section{Analytic and Sampling Methods}

There are various technical fields of research, arcane to the public but essential to occupational and environmental health, for which NIOSH serves as a national and world leader. One of these is the devel opment and validation of "analytic methods," which are used to measure levels of toxicants to which people at work or in the environment are exposed. The measurements are used by researchers to identify hazardous conditions and evaluate the effectiveness of heal th interventions and by employer and regulatory programs to manage risks. For more than 25 years, NIOSH has maintained and expanded the "NIOSH Manual of Analytic Methods," a resource comprising the state-of-the-art methods used by more than 1,700 laboratories throughout the United States, and by laboratories around the world. NIOSH has added 27 new or revised analytic methods since 1995. Some prominent examples are:

- A method for assessing the effectiveness of control measures for reducing exposure of workers, patients, and the public to airborne Mycobacterium tuberculosis.

- A method for rapidly detecting soil contaminated with Histoplasma capsulatum, which can cause histoplasmosis, an infectious respiratory disease risk of particular concern for workers in agriculture and construction. The method reduces the time needed to detect soil contamination from two months to two days, a dramatic breakthrough for research and prevention activities.

- Three methods for assessing exposure to asphalt fumes, used to design control systems to reduce exposures in the paving industry.

- A method for monitoring airborne levels of el emental carbon (a surrogate for diesel exposure). This method has been recommended by EPA for monitoring compliance with a standard under the Clean Air Act.

- A method of exposure assessment for electric and magnetic fields (EMF) that will enable occupational and environmental health studies to address previous limitations believed responsible for some of the conflicting results of epidemiologic research evaluating potential cancer risks of EMF.

- A method for on-site measurement of hexavalent chromium, a carcinogen being considered by OSHA for rulemaking. 
Additionally, NIOSH, in partnership with the American Industrial Hygiene Association, also performs the quality assurance function for industrial hygiene laboratories throughout the United States.

\section{Biomarker Research}

NIOSH develops biological monitoring methods to assess workers' exposure to chemical agents. Some examples in 1999 were:

- Urine tests for assessing exposure of agricultural workers to metolachlor, a herbicide widely used in the production of corn.

- Urine tests evaluating hormonal constituents for evaluating women's infertility, to identify reproductive hazards in the workplace and environment and of potential use in medical practice.

- A new method to detect human genotoxic damage from occupational and environmental exposure to polycyclic aromatic hydrocarbons.

\section{Engineering Research}

NIOSH conducts a wide variety of engineering research with a critical role in prevention. Since 1995, NIOSH scientists have filed for patents on 21 engineering innovations. Some examples illustrating the range of these contributions since 1995 include:

- A device for automatically shutting down gasoline engines used indoors (e.g., generators and compressors) to prevent carbon monoxide poisonings and fatalities.

- Break-through technology for developing a non-invasive tool to test pulmonary function, for research on respiratory diseases.

- A superior method for testing hearing protection devices, used by up to 30 million workers exposed to damaging levels of noise, and also by people with hobbies (e.g., woodworking) and chores (chainsawing, leaf blowing). The American National Standards Institute has published the method in its consumer guidelines.

- An automatically deployable roll-over protection device for tractors used in low-clearance areas such as orchards and animal confinement buildings.

- A "strain index calculator" by which ergonomists can analyze risk for upper extremity musculoskeletal disorders for repetitive work tasks and estimate the effects of changes in job tasks to reduce the risk.

- A device for determining when protective clothing worn by workers to prevent chemical exposures becomes ineffective. 


\section{Research Partnerships}

The implementation of NORA is being accomplished through regular teamwork among groups that, in total, represent more than 200 organizations in the public and private sectors. This network is continuously raising new opportunities for research partnerships between $\mathrm{NIOSH}$ and public and private employer organizations, allowing NIOSH to not only advance research, but see the findings of research immediately translated into prevention programs.

\section{Asphalt Partnership}

NIOSH formed a partnership with the industries involved in asphalt paving (paving companies and paving machinery manufacturers), labor, and OSHA to reduce worker exposure to asphalt fumes during highway paving. The partnership itself was a significant milestone. Many occupational health and safety concerns, including asphalt fumes, generate substantial controversy and confrontation over imperfect science and regulatory strategy. Despite differences of opinion about the health effects of asphalt, the partners agreed on the fundamental point that worker exposures should be reduced. This led to an unprecedented accomplishment: 100 percent of the industry voluntarily agreed to implement the new technology. In less than three years, asphalt exposures to workers were reduced by 80 percent.

The partnership was a finalist in the Innovations in Government Award Program in 1998. Its success has inspired additional NIOSH public-private partnerships addressing similarly contentious problems, including reducing nitrous oxide exposure among workers in dental offices and diesel exposure among underground miners.

\section{Health Care Worker Partnership}

A partnership formed in 1998 with the Department of Veterans Affairs (DVA) has potential for greatly expanding research focused on the health and safety of health care workers. DVA is the largest managed care organization in the United States, with more than 220,000 employees and 700 health care facilities and home care units. The partnership has initiatied joint research to address the substantial problem of latex allergy. The collaboration with DVA is broad-based, however, with the global aim of improving occupational safety and health for health care workers.

The first accomplishment of this partnership, working with OSHA and the Agency for Healthcare Research and Quality (AHRQ), is to bring national focus to the link between occupational safety and health conditions of health care workers and the quality of health care provided to patients. This relationship may figure substantially in the prevention of "medical errors," an issue that has received extensive media coverage and 
congressional interest as a result of a recent Institute of Medicine (IOM) study.

NIOSH has the lead in developing a research agenda in the area and is organizing with its federal partners a national conference to identify best practices to concurrently improve the health and safety of health care workers and patients.

\section{Other Partnerships}

- Retail Industry: In collaboration with Wal-Mart, completing what promises to be the most definitive study to date on the effectiveness of back belts for reducing the risk of back injury and low back pain.

- Health Care: Evaluating the effectiveness of a comprehensive strategy implemented in Illinois and Missouri by the Barnes Jewish Christian Health System to prevent back injuries among nursing home workers.

- Construction Industry: Collaborating with Anthony Crane Operators, the largest crane rental company in the U.S. , to evaluate the effectiveness of operator certification in preventing fatalities, injuries, and property damage resulting from crane use.

- Automobile Manufacturing: Researching jointly with General Motors and the United Auto Workers to prevent back injuries, respiratory diseases caused by exposure to aerosolized metal working fluids, and effects of exposure to noise. Developing through a Cooperative Research and Development Agreement with Ford Motor Company a state-of-the-art data system for improving the effectiveness of hearing conservation programs.

- Appliance Manufacturing: Developing improved ergonomics to reduce musculoskeletal disorders in production work. 


\section{Strategic Goal 2: Develop a System of Surveillance}

Understanding and preventing work-related injuries and illnesses requires focused efforts to identify, quantify, and track both health outcomes and their associated workplace conditions. Occupational safety and health surveillance activities provide the ongoing systematic collection, analysis, interpretation, and dissemination of data needed for prevention. The ability to survey and assess the state of occupational safety and health has improved over time, but substantial challenges remain. Occupational health and safety surveillance data are fragmented and have substantial gaps. As the primary agency for occupational safety and health research, NIOSH plays a critical role in enhancing the generation, access to, and use of surveillance data.

\section{State-Based Surveillance}

NIOSH funds state-based surveillance programs in 25 states. The objectives of these activities are to estimate the magnitude of occupational health and injury problems, to determine whether they are increasing or decreasing, and to increase and target prevention activities.

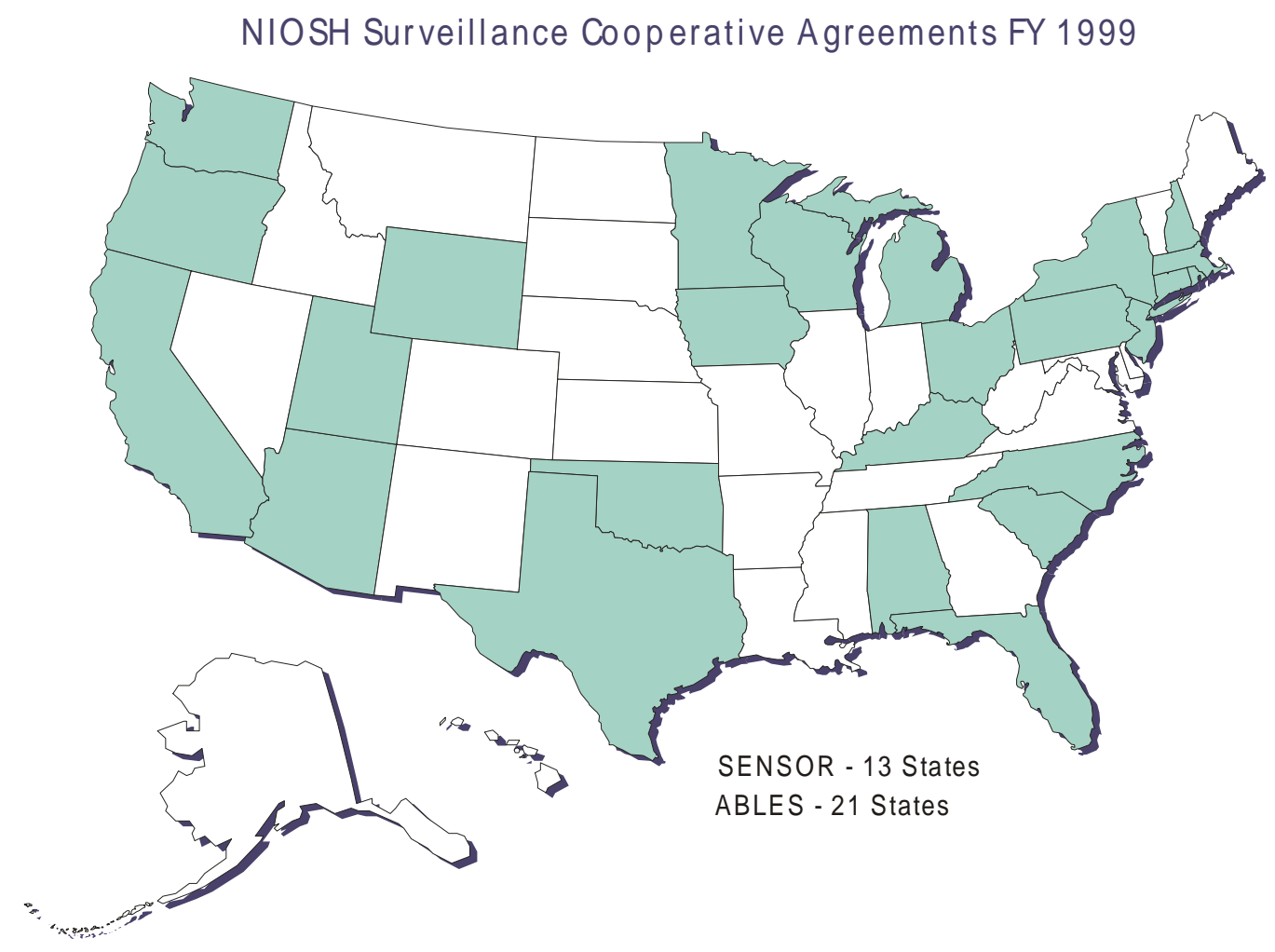




\section{Sentinel Event Notification System for Occupation Risk (SENSOR)}

The SENSOR program is a collaborative effort with 13 State health departments to improve recognition and prevention of occupational sentinel health events. Events targeted include acute pesticide-related illness, amputations, asthma, burns, carpal tunnel syndrome, dermatitis, noise-induced hearing loss, silicosis, and youth injury.

Recent examples of the impact of SE NSOR programs:

- Underutilization of Workers' Compensation - State health departments in Michigan, New Jersey, and Washington State demonstrated gross underutilization of workers' compensation for occupational illnesses: less than 43 percent of workers with silicosis and only 25 percent of workers with occupational dermatitis filed for compensation. These findings are relevant for interpreting workers' compensation data as a source of surveillance, educating workers on the use of workers' compensation systems, and reducing barriers to reporting and claiming compensation for occupational injuries and illness.

- Noise-induced Hearing Loss - The state health department in Michigan identified that four out of five companies investigated have inadequate hearing conservation programs and followed up by providing technical assistance and educational materials.

- Burns - The state health department in Colorado identified deep fryers in restaurants as a leading cause of work-related burns resulting in hospitalization, worked with the state restaurant association to develop a hazard alert, and distributed the alert state-wide during inspections by public health sanitarians.

- Asthma - State health departments in California, Massachusetts, and Michigan have coordinated surveillance efforts for occupational asthma, and are using the data to identify prevalent environmental causes and the industries where they occur, many of which were previously unrecognized (the pickle-packing industry, beet sugar processing, glutaraldehyde-induced asthma in dental offices, and rose hips in the pharmaceutical manufacturing industry,).

\section{Adult Blood Lead Epidemiology Surveillance (ABLES)}

Twenty-eight states participate in the NIOSH ABLES effort to identify and count cases of elevated blood lead levels among U.S. adults. With NIOSH support, 21 of these states collect data on blood lead levels from local health departments, private health care providers, and from reporting laboratories. The States use these data to follow-up with physicians, target on-site inspections of work sites, provide referrals to cooperating agencies in the event enforcement action is necessary, and to target efforts to prevent continuing exposures. 
Recent examples of the impact of the ABLES programs:

- Quantification of the national burden of work-related elevated blood lead levels and the ability to track these data over time.

- Identification of the number of new cases of elevated blood lead levels in ABLES states since 1996.

- Reductions in blood lead levels among road construction workers in Connecticut by 50 percent, resulting in workers' compensation savings as well.

- Adoption of a resolution by the Council of State and Territorial Epidemiologists to achieve national reporting of elevated blood lead levels among adults; this is important as NIOSH advances efforts to establish the precedent for nationwide reporting of occupational illnesses.

- Development of ABLES programs in nine additional states.

- OSHA adoption of reduced adult lead exposures as a goal in its strategic plan, and use of ABLES to track progress.

- Inclusion in Healthy People 2010 of a goal to reduce adult lead exposures and reliance on ABLES to track progress.

\section{National Injury Surveillance}

In 1998, an estimated 3.6 million occupational injuries and illnesses were treated in hospital emergency departments across the U.S. This represents an annual rate of 2.8 injuries or illnesses per 100 workers, with men incurring almost twice the rate of injuries and illnesses as women (3.4 versus 1.8 per 100).

Estimates such as these are made possible due to a collaborative effort between NIOSH and the Consumer Product Safety Commission to collect work-related injury and illness information from a national hospital sample through the National Electronic Injury Surveillance System (NEISS). As one of the largest U.S. occupational injury surveillance systems, NEISS collected information characterizing injuries and their causes on more than 47,700 cases in 1998. The large number of cases collected makes NEISS uniquely able to characterize injuries in populations and industry sectors, and to categorize injuries at a level of detail critical to prevention activities. This injury information supplements data collected in another large injury survey by Bureau of Labor Statistics (BLS) that focuses only on private industry, with an emphasis on larger employers. Additionally, much greater detail and unique insights into injury circumstances, safety practices, and worker perceptions are being gained through NEISS in-depth telephone interviews 
that have been conducted with special populations of workers, such as youth, older workers, and children in agricultural settings. These injury followback studies help target and tailor injury prevention programs and influence health and safety regulations. NEISS data are published by NIOSH researchers in a number of venues, such as journal articles, the Morbidity and Mortality Weekly Report, and hazard alerts that are distributed widely among U.S. employers.

An area in which NEISS has made an exceptional impact since 1995 is on the safety of working youth (under the age of 18). NEISS accomplishments in this area:

- Documented high rates of work injuries among working youth, stimulating and supporting national and state programs targeting protection of young workers.

- Provided a basis for extensive educational activities by NIOSH to inform schools, youth, and their parents of measures to assure safe work experiences among youth.

- Showed that proposed changes to relax the restrictions of U.S. child labor laws could increase injury among working youth.

- Provided surveillance data for tracking Healthy People 2010 objectives to reduce occupational injury among adolescent workers.

\section{Surveillance Agendas for the $21^{\text {st }}$ Century}

In 1999, NI OSH conducted two major strategic planning efforts, using the NORA model to involve hundreds of stakeholders in defining surveillance agendas for occupational safety and health. NIOSH planning produced a unified, detailed agenda with five major goals:

- Improve the national surveillance system.

- Improve surveillance at the State level.

- Develop better methods of surveillance for high risk or underserved populations.

- Improve surveillance conducted by private sector organizations.

- Increase research on surveillance methods.

Each of these goals includes a highly specific listing of objectives and implementation steps for their accomplishment. In addition, with extensive stakeholder involvement, NIOSH prepared a detailed strategic plan for devel oping a system of occupational hazard and exposure surveillance, an effort that NIOSH is now leading with leveraging of resources from other federal agencies (e.g., OSHA). 


\section{Strategic Goal 3: Increase Prevention Activities}

NIOSH conducts three programs of investigations similar to the "outbreak" type epidemiologic investigations carried out by other programs of the CDC: Health Hazard Evaluations(HHEs), Fatality Assessment and Control Evaluation (FACE), and Firefighter F atality I nvestigation and Prevention (FFIP). These NIOSH programs, respectively, investigate the occurrence of occupational health problems among workers of individual employers, incidents in which workers are fatally injured, and fatalities among fire fighters. The programs draw upon the extensive research and technical expertise of the Institute, both to evaluate the causes of disease and injury and to design and recommend solutions to prevent future occurrences. The programs serve multiple purposes including:

- Solving individual employers' safety and health problems.

- Providing instructive case studies of risk findings and prevention recommendations to employers nationally and globally with similar problems.

- Directing research by NIOSH and others to address emerging and unresolved problems.

\section{Health Hazard Evaluation (HHE) Program}

NIOSH conducts about 300 evaluations annually of potential health problems at worksites, derived from our statutory obligations to be responsive to requests from employers, employees, and other governmental entities to assess the potential work-relatedness of health problems and recommend effective prevention and remedial strategies (see chart at top of next page).

The HHE program has played a key role in the recognition and assessment of many of the major emerging occupational health problems of the past three decades, such as occupational asthma, cumulative trauma disorders, and indoor air quality. It has also provided industry-wide expertise needed to mount industry-based research and prevention initiatives. In the 1970's and early 1980's, HHEs informed activities addressing carcinogens and respiratory diseases in manufacturing and mining. Today, HHEs are driving initiatives targeting the service sector and particularly health care, where NIOSH has conducted 135 HHEs since 1995, addressing the whole range of problems from job stress and ergonomics to infectious disease transmission and reproductive toxicants. 


\section{Health Hazard Evaluations}

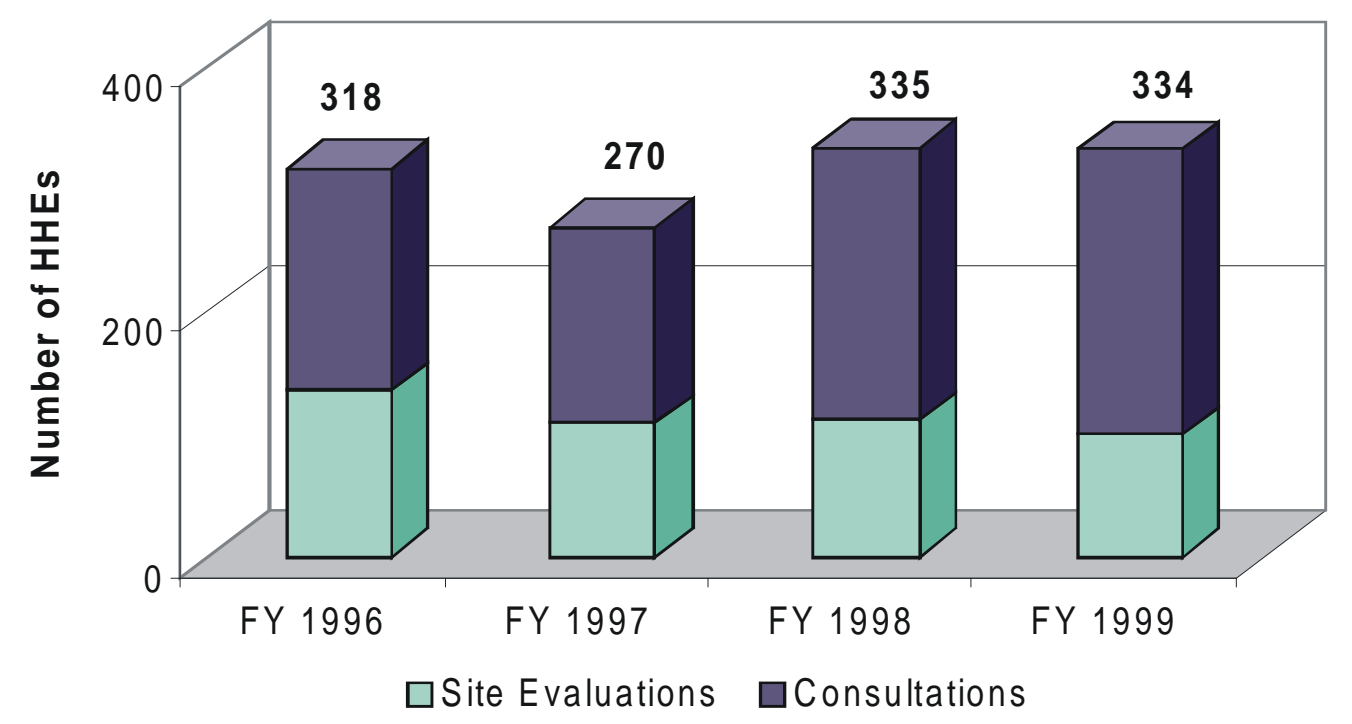

A 1998 HHE which led NIOSH to the identification and confirmation of "Flock Worker's Lung," a new chronic lung disease, illustrates the importance of HHEs to the entire spectrum of research and prevention in occupational safety and health.

The disease is caused by occupational exposures to nylon "flock," a surfacing product used widely in the auto industry, for upholstery, and in the textile industry. NIOSH laboratory research has found nylon flock particles to be more inflammatory than silica, a highly toxic occupational dust with the potential to cause severe lung diseases. The American Association of Fiber Manufacturers has distributed information from the NIOSH HHE and laboratory studies to their membership in a toxicity alert and Dupont has initiated a program of research, which is confirming the NIOSH findings.

Reports of HHEs are disseminated in print, through web-based electronic publication, CD-ROMS, and findings are routinely reported by the national trade press in occupational safety and health publications. 


\section{Other Examples of Important HHEs Since 1995:}

- Identified a widespread potential health hazard to miners associated with a chemical additive used in dust suppression systems in mines.

- Identified work processes and ventilation deficiencies in a medical waste treatment facility that caused an epidemic of tuberculosis among employees.

- Identified product mislabeling as the cause of an outbreak of pesticide poisonings, prompting EPA action and remedy by the manufacturer.

- Identified high levels of mercury exposures among the emerging industry of household battery recycling.

- Identified and prevented continued contamination of the homes of workers exposed to beryllium (a highly toxic metal) at a machine shop.

\section{Fatality Assessment and Control Evaluation (FACE) Program}

The FACE program is currently active in 20 states. NIOSH funds 15 state-based projects through cooperative agreements and conducts investigations in 5 additional states through an intramural program.

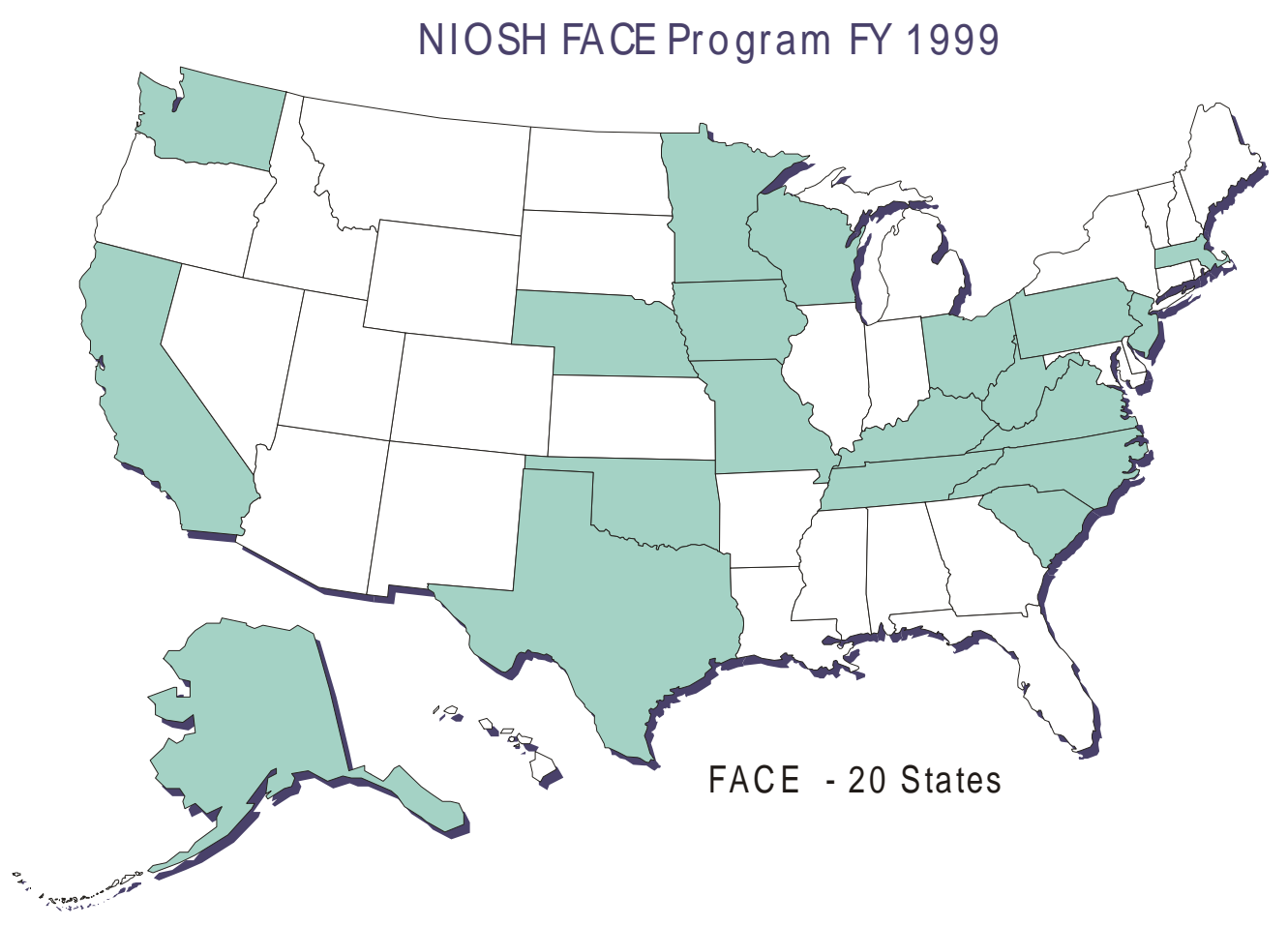


The purpose of FACE is to identify work situations at high risk for fatal injury and formulate and disseminate prevention strategies to employers, workers, unions, public agencies, and others in a position to advance prevention. In-depth investigations of selected types of fatalities identify factors that contribute to an event, and inform the development of safety recommendations. Information from these investigations is used in health communication efforts and public policy. These activities occur at both the national and state level. From 100 to 200 FACE investigations are conducted annually.

Examples illustrating the use of FACE investigations for prevention:

- In 1999, NIOSH published an Alert: Preventing Injuries and Deaths of Workers Who Operate or Work Near Forklifts. Nearly 100 workers are killed and another 20,000 are seriously injured in forklift-related incidents each year in the United States. The Alert highlighted investigations conducted by NIOSH staff and investigators in NIOSH-funded programs in California and Indiana and provided recommendations for employers and workers, including a tear-out sheet summarizing recommendations to be posted at worksites.

- In 1995, the New J ersey FACE program investigated the electrocution of a 20-year-old lifeguard employed at an apartment complex. He had just checked in for work. As he tried to adjust the chlorine pump, his leg contacted the metal pump housing, which had been energized with 220 volts. An inspection found faulty wiring had allowed the pump housing to become energized. In response to this finding, the New J ersey Department of Health issued a health alert bulletin warning owners and employees of public swimming pools of this hazard and encouraging inspections of pool electrical systems. State legislation enacted in F ebruary, 1999, requires periodic electrical inspections and bonding and grounding certificates for swimming pools, spas, and hot tubs, to improve safety of workers and the general public.

- Several FACE investigations since 1995 have evaluated causes of fatality among workers constructing or maintaining communication towers. The widespread use of wireless communications services has fueled accelerated construction of towers to hold transmitting devices for cellular phones, personal communication services, and television and radio broadcast antennas. The Federal Communications Commission estimates that at least 75,000 towers have been constructed in the United States, and industry groups estimate that over 25,000 new towers will be erected each year. NIOSH estimates the risk of fatalities among this workforce is extremely high, between 49 and 468 deaths annually per 100,000 workers, versus 5 per 100,000 in industry overall. NIOSH efforts are informing voluntary and regulatory approaches to this major emerging safety problem. 


\section{Firefighter Fatality Investigation and Prevention (FFIP) Program}

The United States depends on approximately 1.2 million firefighters, five out of six of whom are volunteers, to protect its citizens and property from losses caused by fire. On average, 100 firefighters die on the job annually and approximately 95,000 are injured. Fatalities and injuries occur from cardiac arrest, internal trauma, asphyxiation, crushing injuries, burns, drowning, electrical shock, and other causes. In 1998, NIOSH initiated a program to reduce firefighter line-of-duty deaths and injuries through surveillance, investigations of all fatalities, and development and dissemination of recommendations.

Individual reports of FFIP investigations have been highly valued by local fire departments across the country, which reproduce the reports for further distribution. The investigations have also provided the basis for several important public health actions taken by NIOSH and partners:

- An investigation identified a burn and explosion hazard to firefighters, other emergency medical workers, victims of fires, and others requiring emergency medical care. The hazard involved a type of valve, called a regulator, that controls the flow of oxygen from equipment used to resuscitate firefighters and other victims requiring emergency administration of oxygen. Through investigation of the cause of an explosion which severely burned several firefighters and previous similar incidents, NIOSH identified the use of aluminum in certain regulators as the cause. NIOSH and FDA responded to this hazard by jointly issuing a public health advisory which has had an immediate impact, producing a recall and redesign by the manufacturer of the regulators and remedial efforts in the public safety and health care industries.

- Investigations of fatalities and injuries identified hazardous conditions associated with structural collapse and fires involving propane tanks. Structural collapse is the leading cause of firefighter fatalities. NIOSH worked with the firefighting industry to develop and disseminate nationally recommendations to improve safety in these circumstances. 


\section{Scientific Support for Public Health Policy Development}

As illustrated in examples through the preceding sections, NIOSH conducts, analyzes, and translates an enormous amount of research each year in support of public health policy. This work is reflected in policy recommendations issued by $\mathrm{NIOSH}$, scientific input into rulemaking and the development of enforcement procedures by OSHA, MSHA, EPA, and other public agencies.

\section{Recommending the Development of New Standards}

Under the Occupational Safety and Health Act and Federal Mine Safety and Health Act, NIOSH is authorized to recommend new occupational safety and health standards to OSHA and MSHA. These recommendations take the form of "Criteria Documents." These contain comprehensive reviews of the scientific literature evaluating a particular occupational hazard, including risk characterization and/or quantification and feasible prevention strategies. From 1995 to 1999, NIOSH transmitted recommendations for five standards to OSHA and MSHA.

For example, in 1998, NIOSH recommended to OSHA development of a comprehensive standard to protect the more than one million workers exposed to metal working fluids. OSHA has proceeded with these comprehensive recommendations to undertake a standards advisory committee approach to regulatory action.

\section{Scientific Contributions to Rulemaking}

Since its inception, NIOSH has been a principal scientific contributor to rulemaking by OSHA and MSHA, providing research input and recommendations for every standard that has been proposed or promul gated. In addition, NIOSH provides scientific support and recommendations to other agencies that devel op regulations or mandatory guidelines affecting occupational safety and health, including the EPA, DOE, and others. This input may include elements from NIOSH criteria documents, such as epidemiologic and toxicologic reviews, control technol ogy feasibility assessments, quantitative risk assessments, and prevention recommendations. (see chart at top of next page).

\section{Participating in Policy Development Activities}

National Science and Technology Council

$\mathrm{NIOSH}$ is the only DHHS representative on the National Science and Technology Council, Subcommittee on Construction and Building, which was organized in 1994 to coordinate the work of 14 federal agencies in enhancing the international competitiveness of U.S. industry, public and 


\section{Scientific Contributions to Rulemaking}

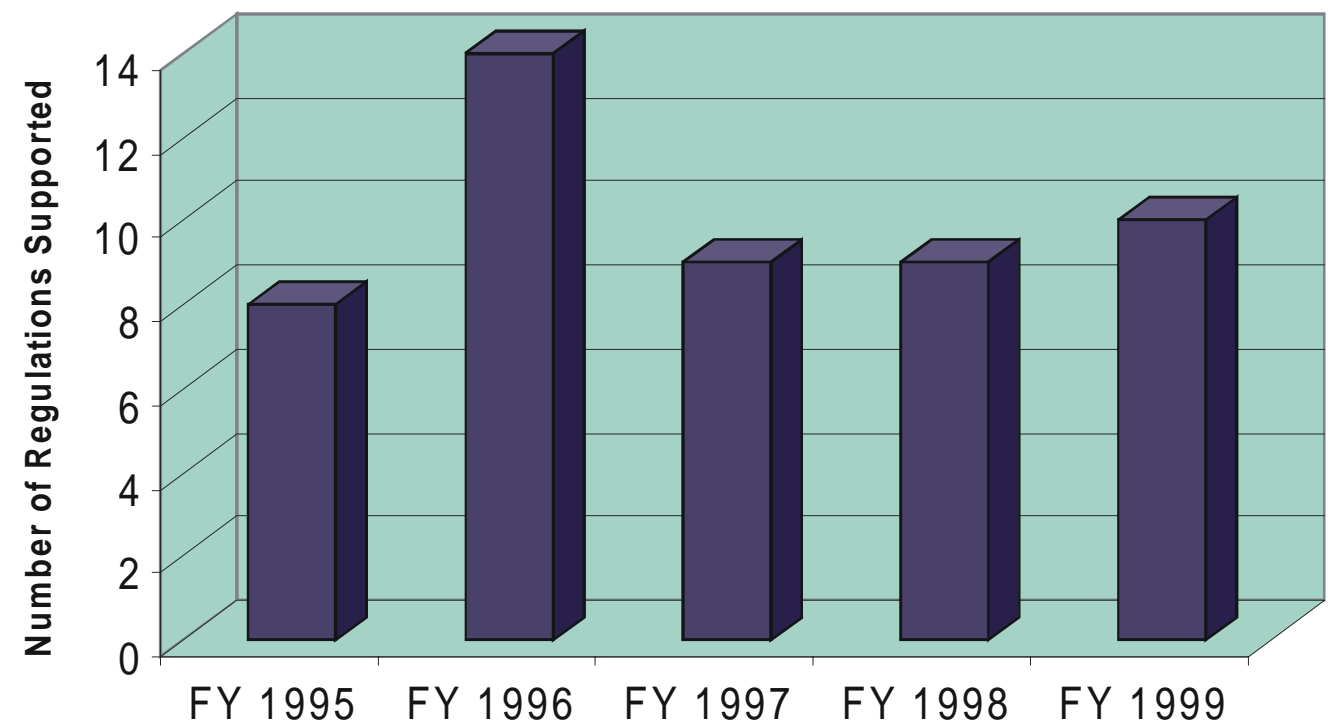

worker safety, and environmental quality through research and development. The Subcommittee relies on NIOSH expertise to identify and research current and emerging occupational hazards to construction workers, as well as interventions to reduce exposures.

National Economic Council

$\mathrm{NIOSH}$ is the lead agency for HHS participating in two interagency activities convened by the National Economic Council (NEC), charged with evaluating:

- Draft legislation to create a program to provide workers' compensation benefits for DOE contractor workers with chronic beryllium disease and beryllium sensitivity and the basis for broader compensation to DOE workers for other work-related exposures and outcomes.

- Proposed legislation to address the need for the efficient resolution of personal injury claims arising from asbestos exposure. NIOSH has played a major role in helping the group examine and evaluate the medical criteria included in both the proposed bills and several state-based settlement agreements. 


\section{International Contributions to Policy}

As a global leader, NIOSH works with international agencies to develop international policies in occupational safety and health. NIOSH contributions in 1999 include:

- Development of a Concise International Chemical Assessment Document (CICAD) on silica for the WHO/I nternational Programme on Chemical Safety and coordination of scientific reviews for eight additional CICADs.

- Review of chemical testing guidelines developed by the Organization for Economic Development and Coordination (OECD).

- Collaboration with the Dutch Expert Committee on Occupational Standards, Health Council of the Netherlands on the update of 100 exposure limits.

- Concluded leadership of an international effort, conducted at the request of the International Labour Organization (ILO), to revise the standard classification system for radiographic recognition of the pneumoconiosis, resulting in a new system accepted by the ILO in 1999.

\section{Providing National Respirator Certification and Quality Assurance}

$\mathrm{NIOSH}$ is the only U.S. agency responsible for ensuring that the more than six million workers who rely on respirators for protection have safe and effective devices. The program establishes, through regulation, performance and design requirements for respirators used by workers, and evaluates and assures the quality of respirators produced. In 1995, NIOSH promulgated a new standard for evaluating the most commonly used types of respirators. The standard has unl eashed an unprecedented level of innovation in this product market. In conjunction with this regulatory change, $\mathrm{NIOSH}$ devel oped an innovative electronic certification process that increased NIOSH certification productivity enormously. As a result of these actions, NIOSH has certified 3,650 new respirator models since 1995 (55 percent of all respirators NIOSH has certified since 1972). 


\section{Respirators Certified by NIOSH}

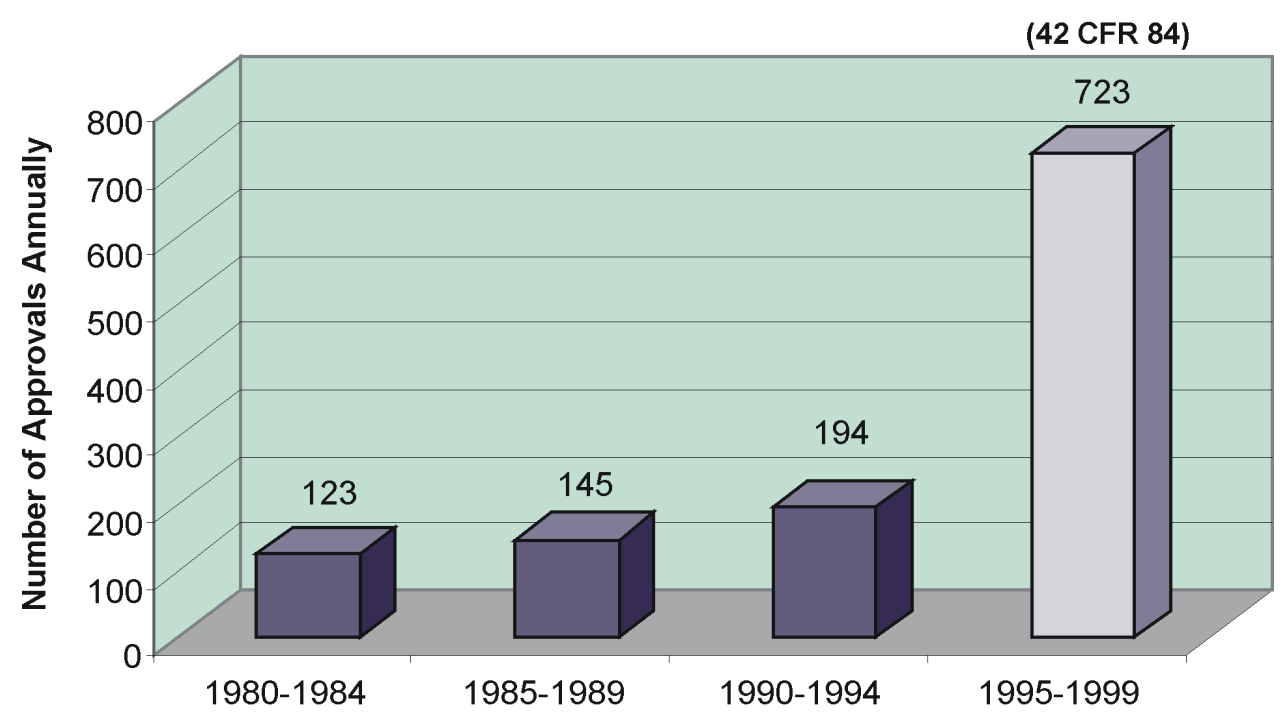

Innovation in the respirator market has increased, and along with it, quality and cost savings. Respirator manufacturers are providing a generation of more economical products with less leakage, more efficiency and less breathing resistance. These factors have been enormously important to the health care industry, where workers themsel ves don respirators to protect against tubercul osis infection. A cost analysis of Department of Veterans Affairs (DVA) facilities in 1995 estimated the economical new respirators available for protection from tuberculosis would save the DVA \$16 million annually, suggesting enormous savings for the health care industry as a whole.

In addition to certifying respirators, NIOSH conducts manufacturing site and product audits to assure the quality of products delivered to the market, and provides technical assistance to employers, workers, and others. An average of four to six recalls are issued annually for faulty products (posing risk to worker safety) identified through this quality assurance activity.

The respirator program will have a critical new role to play as federal, state, and local emergency response agencies devel op capacity to address the threat of biological terrorism. In its 1999 report, Chemical and Biological Terrorism: Research and Development to Improve Civilian Medical Response, the Institute of Medicine (IOM) identified as its second priority increased research to devel op more protective respirators and other protective clothing and equi pment. Certification and research activities of the NIOSH respirator program are being requested by key stakeholders, including federal partners and labor and industry groups. 


\section{Strategic Goal 4: Provide Information, Training, and Capacity}

\section{Information}

As illustrated in examples throughout this report, NIOSH delivers various types of informational products, in print and el ectronic form, to diverse audiences ranging from laboratory researchers to employers, workers, and the public at large. These are categorized as follows:

Policy Documents include Criteria Documents, which recommend a comprehensive safety or health standard; Current Intelligence Bulletins, which provide critical new scientific findings and conclusions of policy relevance; Hazard I dentifications of unrecognized threats to health or safety; and Alerts of hazardous conditions and prevention strategies provided to management, labor unions, workers, and public health and regulatory agencies.

Technical and Surveillance Reports provide tools and information used by scientists, engineers, and safety and health practitioners for research and prevention activities. (Not included here are the peer-reviewed journal publications of NIOSH scientists reviewed under Strategic Goal 1).

Educational Documents provide information for the prevention of work injuries and illnesses, particularly targeting employers, workers, and safety and health managers without formal training in occupational safety and health.

Output of these documents ranges from year to year, depending on the volume of other research activities (these documents are prepared by active scientists), varying production of findings appropriate for publication, and identified needs (see chart at top of next page).

NIOSH documents are often in high demand, providing the latest findings and recommendations to the occupational safety and health community. Some of the most popular federal publications are produced by NIOSH, such as the NIOSH Pocket Guide to Chemical Hazards, which remains, year after year, the leading safety and health document sold by the Government Printing Office (GPO) and among the top ten sellers of all GPO publications. Several important recent NIOSH publications in high public demand are: 


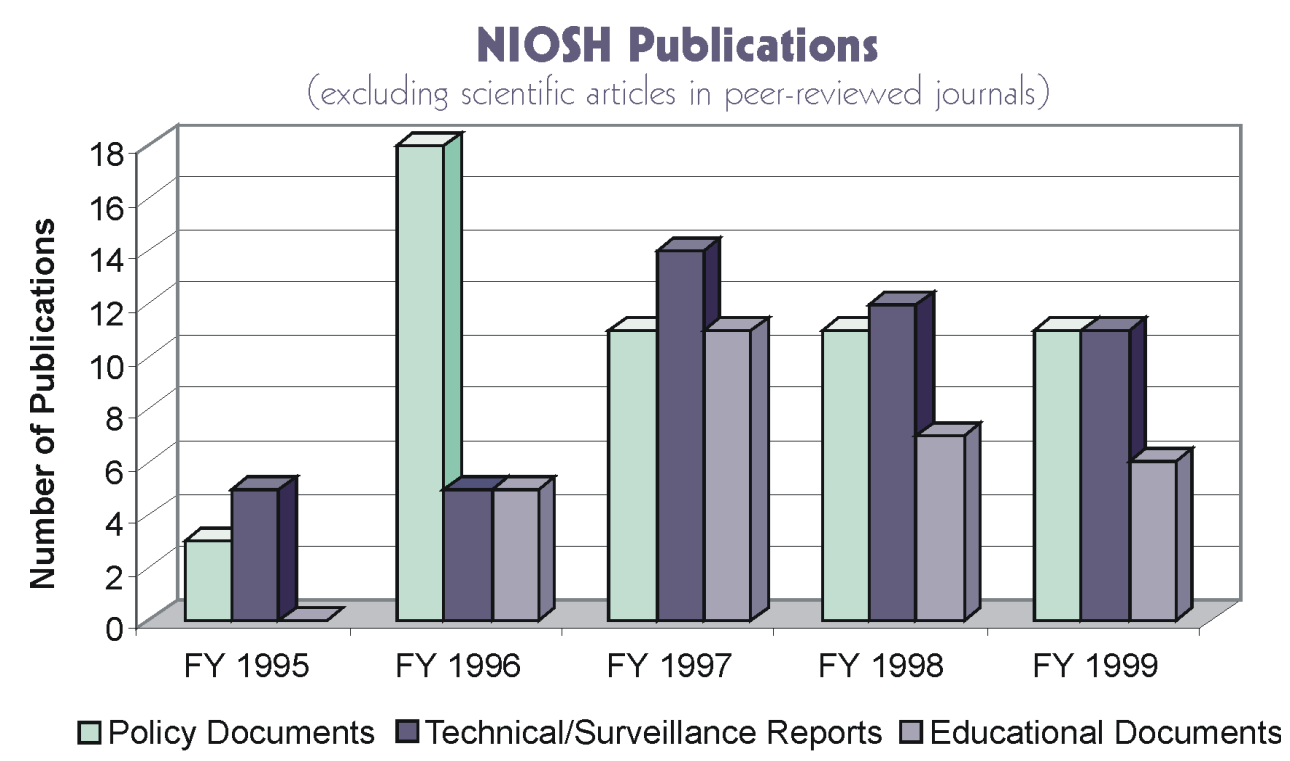

Musculoskeletal Disorders and Workplace Factors: A Critical Review of E pidemiologic Evidence for Work-Related Musculoskel etal Disorders of the Neck, Upper Extremity, and Low Back

In 1997, NIOSH scientists completed the most comprehensive review of the occupational epidemiological literature on musculoskel etal disorders to date. Subsequent to the publication of this review of the scientific evidence, NIOSH's conclusions were supported by a National Academy of Sciences study, as well as a broad community of medical and health experts (including the American Industrial Hygiene Association, the American Public Health Association, the American College of Occupational and Environmental Medicine, the Human Factors and Ergonomics Society, and the American Association of Occupational Health Nurses). Regulatory agencies have relied heavily on the NIOSH document. OSHA used the NIOSH conclusions to draft its proposed workplace ergonomics rules. Moreover, the California Court of Appeals noted that the NIOSH study provided scientific evidence pointing to the need for ergonomics regulation in a 1999 decision to reinstate most provisions of the state's ergonomics standard. The document is accessed an average of 1,550 times per month on the NIOSH web site.

Elements of Ergonomics Programs: A Primer based on Workplace Evaluations of Musculoskeletal Disorders

Another important NIOSH document on musculoskeletal disorders was published in March 1997. This ergonomics primer summarizes NIOSH's practical experience in small and medium-sized 
Other Examples of NIOSH Documents since 1995:

- An Alert describing injury risks to adolescent workers and guidelines for reducing these risks was distributed to every highschool in the Nation.

- An Alert for preventing asthma and deaths among 280,000 workers exposed to disocyanates in the manufacture of foams, fibers, coating, and insulations.

- Handbooks for male and female workers on reproductive hazards in the workplace and guidelines for avoiding these hazards.

- A multimedia CD ROMbased learning exercise for farmers that enables them to think through safety issues and investments within the context of the economic, social, and family issues involved in operating a farm.

- Guidelines for respirator selection and use in the health care industry, for protection against tuberculosis infection. workplaces and describes the basic elements of a workplace program aimed at preventing workrelated musculoskeletal disorders. Numerous companies have turned to the primer for assistance and NIOSH has distributed nearly 40,000 copies of the document, which is also accessed an average of 850 times per month via the NIOSH web site.

\section{Stress...at Work}

J ob-related stress is high among today's workforce. In J anuary 1999, NIOSH published a document that offers employers, human resources personnel, and workers a practical, easy-to-read resource, with real case studies, to help them answer three critical questions: What causes job stress, is there a problem in my workplace, and if so, what can be done to find sensible, meaningful solutions? The stress document received wide press coverage and $\mathrm{NIOSH}$ received more than 55,000 requests for copies in the year of publication.

\section{NIOSH Warns of Hazards of Flood Clean- Up Work \\ $\mathrm{NIOSH}$ information is often used to address} urgent public health and environmental disasters. For example, when the Ohio River flooded in 1997, NIOSH provided key safety information on hazards associated with flood clean-up to 20,000 paid and volunteer workers involved in rescue, clean-up, and reconstruction operations. Since then, NIOSH has routinely served FEMA, state agencies, and the Red Cross to help assure the safety of flood relief operations. 


\section{NIOSH Web Hits}

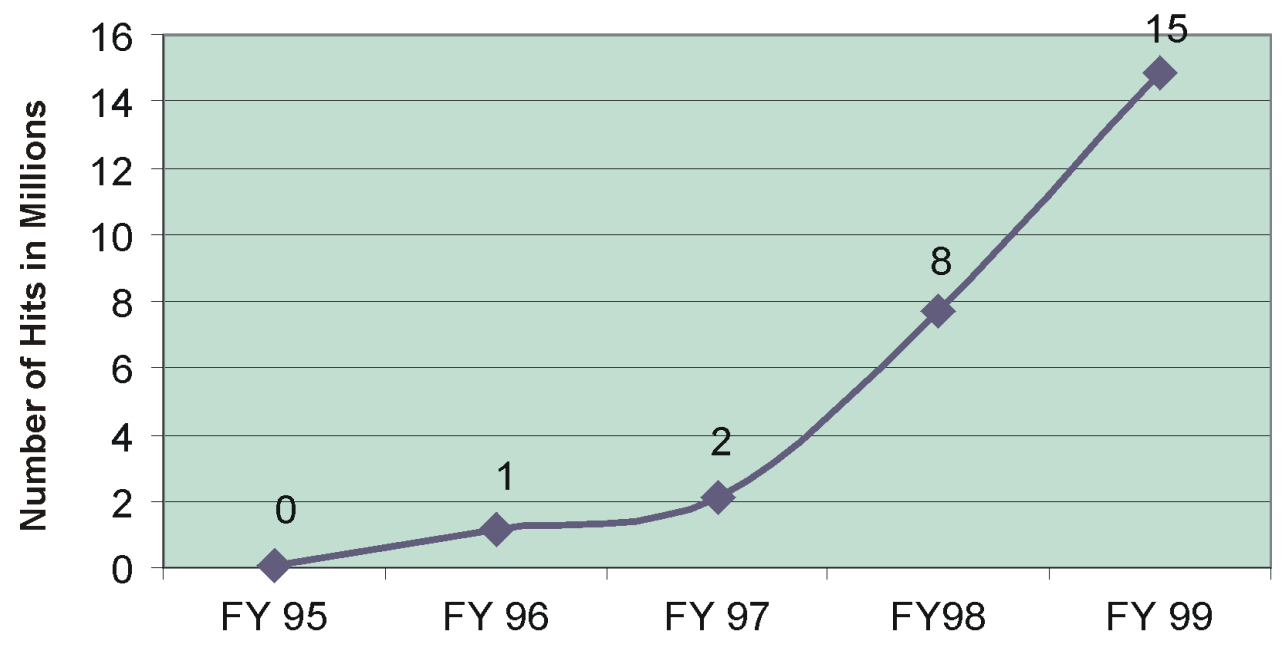

\section{NIOSH Web-based Dissemination}

NIOSH disseminates a high volume of information through its web page, posting 25 percent of the total information disseminated through the CDC website. The volume of demand for NIOSH information through the Internet is increasing rapidly.

\section{1-800-NIOSH}

NIOSH operates a toll-free telephone information service to assist safety and health professionals, employers, workers, and others seeking information or assistance with occupational or environmental health problems. Demand for this service continues to grow. Although the prevention activities of NIOSH staff are generally one or more steps removed from those of the managers, workers, and safety and health professionals who directly save lives with NIOSH information, occasionally, Institute staff find themselves right on the front line of prevention, as two examples from 1998 illustrate:

- A safety manager at a chemical storage terminal in South Carolina called $\mathrm{NIOSH}$ to confirm his selection of organic vapor respirators to protect workers entering a tank containing hydrogen sulfide, which is lethal at high exposures. NIOSH inquiry into the exposure conditions and advice (to conduct the work through a remotely operated device) saved several workers' lives that day. 
- A flight attendant called NIOSH with concerns about the noise levels to which airline employees can be exposed while in flight. After receiving technical assistance from a NIOSH expert on the prevention of hearing loss, the flight attendant petitioned the Chief Executive Officer to change the airline's policy of prohibiting flight attendants from wearing hearing protection. As a result, the company not only reversed its policy, allowing flight attendants to use hearing protection, but also began monitoring noise levels.

NIOSH 800-Number Calls by Fiscal Year

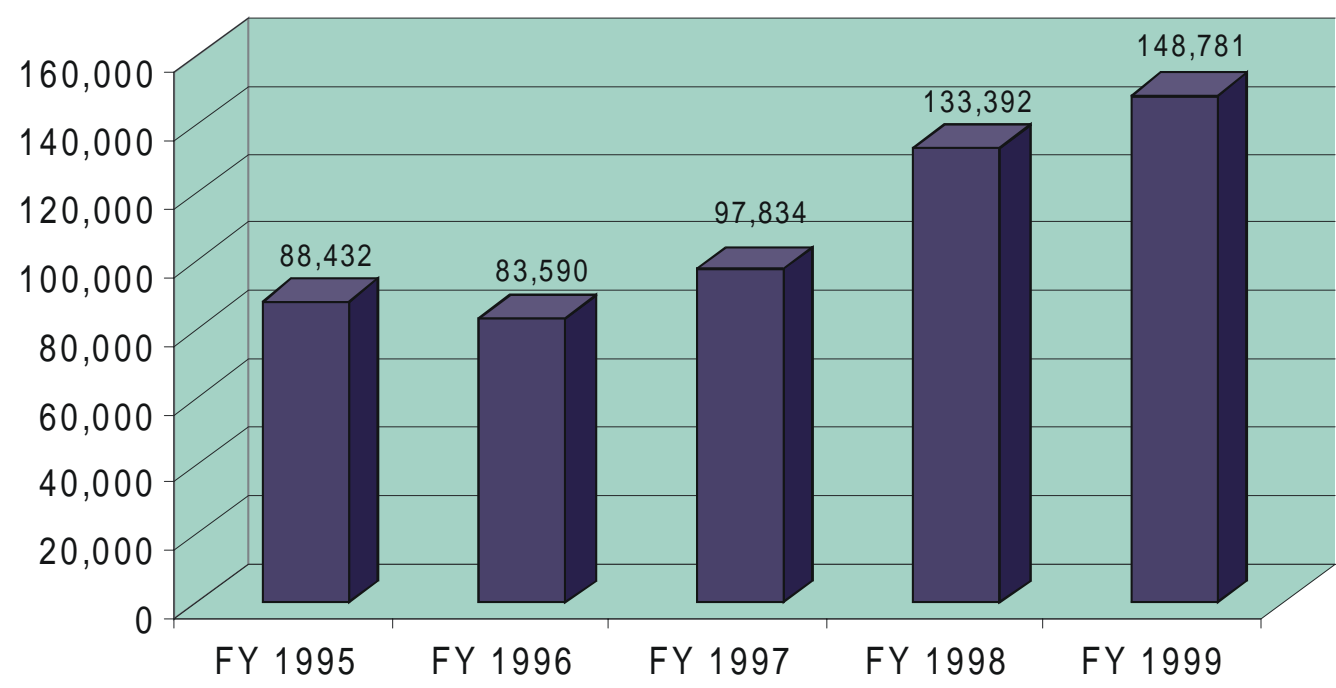

\section{Training Occupational Safety and Health Professionals and Researchers}

Congress passed the Occupational Safety and Health Act in 1970 to "assure safe and healthful working conditions for every working man and woman in the United States" and required NIOSH to provide an "adequate supply of qualified professionals" for achieving this mission. Section 21 (a) of the Act states that "The Secretary ... shall conduct, directly or by grants and contracts (1) education programs to provide an adequate supply of qualified personnel to carry out the purpose of the Act..."

Pursuant to this mission, NIOSH conducts a $\$ 13.9$ million training program comprised of a network of 15 regional Education and Research Centers located at leading universities in 14 states, and 41 training project grants in 26 states and Puerto Rico. 


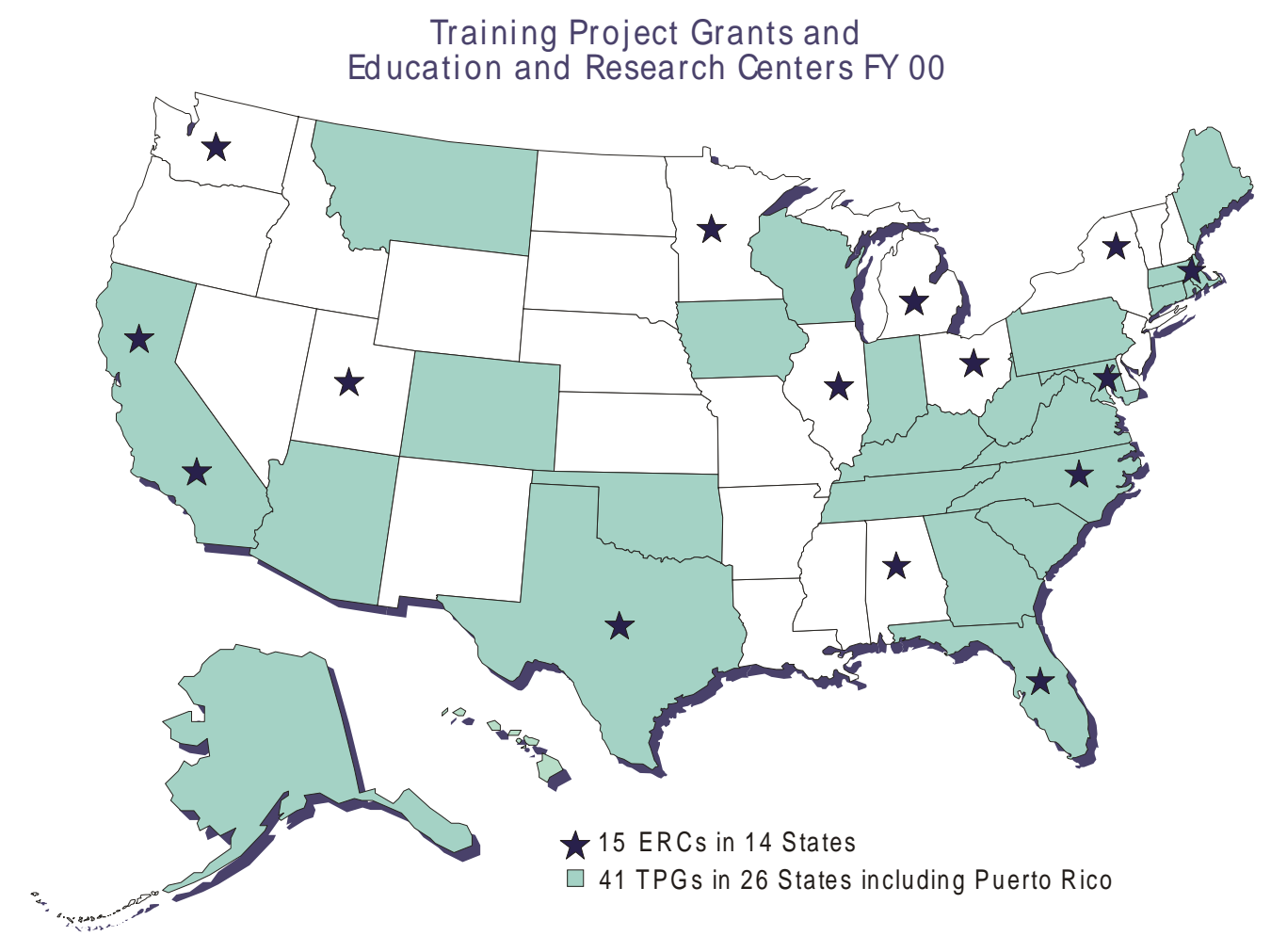

An average of 700 students graduate annually from these $\mathrm{NIOSH}$-supported programs with training in medicine, nursing, industrial hygiene, and safety engineering. NIOSH estimates that about half of the U.S. occupational safety and health professionals graduate from NIOSH-supported programs, mostly at the masters and doctoral levels. NIOSH also funds more than a thousand continuing education courses each year, with upwards of 30,000 participants. Appropriations for training have been steady since the 1980s, and have eroded substantially when adjusted for inflation (see chart at top of next page).

\section{Evaluation of NIOSH Training Programs}

According to a 1995 report by the Inspector General of HHS, about 80 percent of the professionals graduating from NIOSH-funded programs pursue careers in occupational safety and health, with slightly more than half of the graduates working in private industry and the rest in government, academia, or other settings. Many current leaders and occupational safety and health advocates have received training from $\mathrm{NIOSH}$-funded programs. 


\section{O ccupational Safety and Health Professionals} Trained

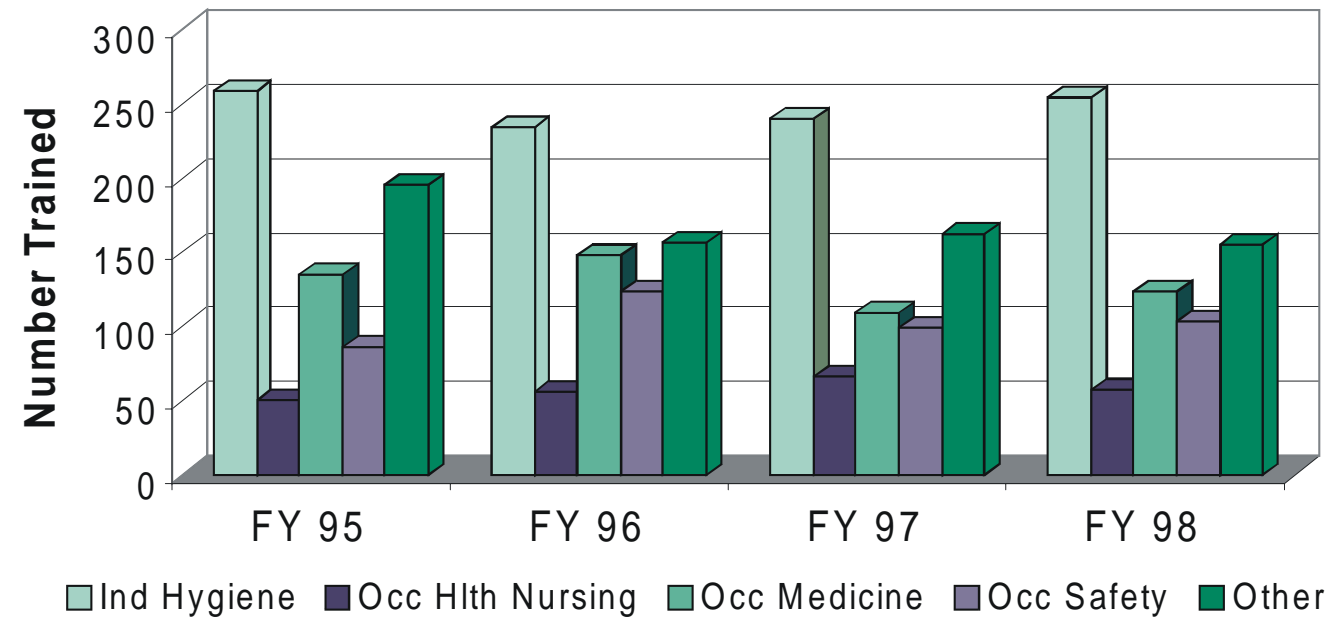

\section{Training Workers}

NIOSH has a secondary role (to OSHA and MSHA) in developing and providing safety and health training for workers. This includes the following activities:

- Training in handling emergencies involving hazardous materials provided by the International Association of Firefighters to 4,500 firefighters and emergency responders annually.

- Training in safe procedures for hazardous waste clean-up workers and lead abatement workers.

- Training graduate psychol ogy students to evaluate the effects on health and productivity of different approaches to the organization of work.

\section{Training Evaluation Research (Worker Training)}

More than 100 OSHA standards for controlling workplace hazards contain requirements for worker training to reduce risk factors for injury and disease. Although it is assumed a trained workforce will be safer and more productive, there is a dearth of empirical data on the factors that determine the effectiveness of a safety training program. To address the issue of training effectiveness, $\mathrm{NIOSH}$ has initiated a program to evaluate, and assist others who evaluate, training programs. Accomplishments since 1997 include:

- An extensive review of the research literature entitled Assessing Occupational Safety and Health Training: A Literature Review; 
- Development of a training intervention effectiveness research model (TIER model), which has already been adopted in four research studies; and

- Completion of an evaluation of safety training conducted by the National Restaurant Association Educational Foundation, finding limited success of a multi-media training strategy.

\section{ITREOH Countries, 1999}

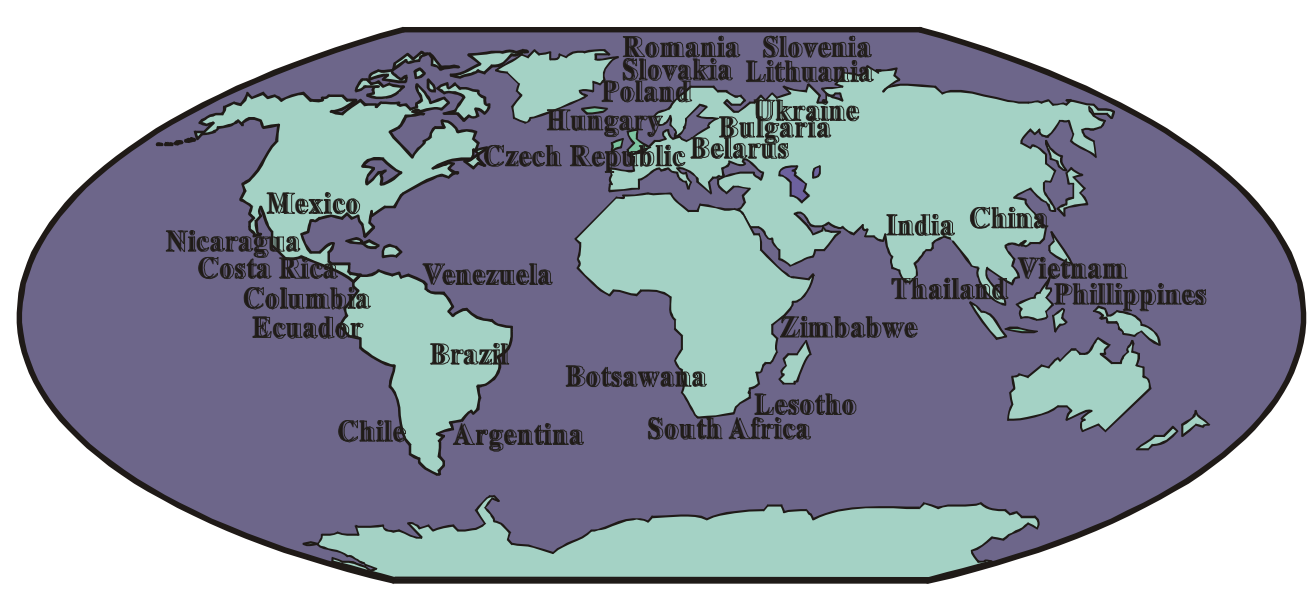

\section{International Training}

Through the International Training and Research Program in Environmental and Occupational Health (ITREOH), NIOSH is a key supporter, with other federal partners, in building capacity to address occupational and environmental health problems in developing countries. Training is provided in a variety of disciplines related to occupational safety and health (e.g., epidemi ol ogy, occupational medicine, industrial hygiene, safety engineering, and toxicology) and is conducted both in-country and in the U.S. at the respective awardee academic institutions.

Since inception of this program in 1995, awards have been made to 13 U.S. academic institutions and training has involved some 28 countries in Africa, Asia, Central Europe, and Latin America. In the first three years of the program, 193 preand postdoctoral trainees came to the United States for long-term training. One hundred in-country courses have been given involving 4,418 trainees and 175 faculty members from U.S. institutions. A total of 234 articles have been published or submitted and 285 presentations have been given by trainees, their mentors, and affiliated scientists. 


\section{New Directions}

NIOSH training programs are building capacity to prepare new leaders and trainers of occupational safety and health practitioners. NIOSH has initiated a Pilot Project Research Training Program to expand NORA research by providing training for researchers who will investigate NORA priorities. NIOSH is also funding a new initiative on occupational health services research training to address the low number of researchers conducting health services research in the field of occupational safety and health.

The work environment has changed greatly since NIOSH began its training programs and many new injuries and illnesses have emerged. The workforce itself is different, with women, minorities, older (over 49) and younger (under 18) workers increasingly contributing to its ranks. Work done under contract, on a part-time basis, and employment in the service industry has also increased-all situations in which occupational safety and health consulting or healthcare may not be provided. In addition, delivery of health services is changing rapidly, and many primary care health providers are inadequately trained in recognition and treatment of occupationally related illnesses and injuries.

To explore the demands on the occupational safety and heal th professional in this changing environment, NIOSH funded a contract with the Institute of Medicine (IOM) to conduct a workforce needs assessment. This will examine the demand for and supply of various disciplines that make up the occupational health workforce, and develop recommendations on how to continue to build a workforce that can respond to the challenges of the future. IOM will issue a report on its finding in mid-2000.

\section{NIOSH Budget History}

$\mathrm{NIOSH}$, like many private sector organizations, is doing more with less, but over a longer haul. In inflation-adjusted dollars, the Institute has yet to regain its budget level from 1980, perhaps representing the only case of long-term funding loss among all Federal health agencies. Had NIOSH sustained growth equal to NIH or CDC overall respectively, its current resources would be two- to four-fold greater (see chart at top of next page).

A few major consequences are the datedness of national estimates of the numbers of workers exposed to known and potential hazards, the continued lack of a national system of state-based surveillance of occupational diseases and injuries, a declining frequency of large epidemiological studies, and overall, an increasing gap in knowledge of the health and safety effects of new work chemicals and technology. 


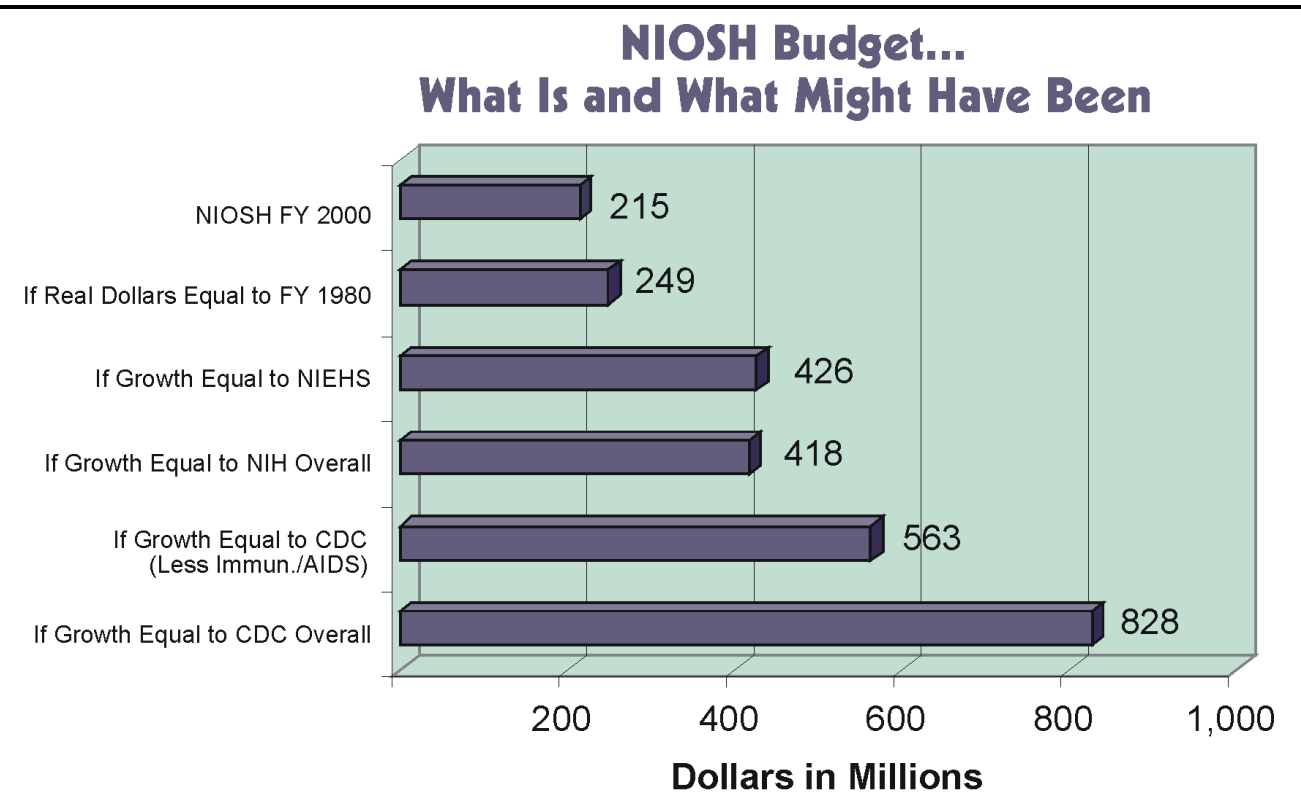

Despite these limitations, NIOSH continues to lead occupational safety and health research and prevention. The Institute has sustained leadership, in part, by using external partnerships to supplement internal resources, and by identifying and building on common interests, whenever possible. The track record illustrated in this report suggests how much more NIOSH could accomplish if it were funded commensurate with its sister programs and agencies. 


\section{Summary and Conclusions}

With concrete examples, we believe this document demonstrates the world leadership of the National Institute for Occupational Safety and Health, as well as the quality, productivity, and impact of its programs. At the same time, workrelated injury and illness continue to exact an unacceptable toll on U.S. workers, as well as on their employers, their families, and society at large. To date, this country has not invested the resources needed to address this significant and evolving public health problem.

$\mathrm{NIOSH}$ has made a vital contribution with the resources available, and has effectively leveraged the activities and resources of other government agencies, the private sector, and the community of health and safety professionals in pursuit of occupational safety and health for U.S. workers. NIOSH is ready to extend its successes into the 21st century and continue its responsible stewardship of this nation's investment in workplace health and safety. 